Article

\title{
Immunoglobulin Tau Heavy Chain (IgT) in Flounder, Paralichthys olivaceus: Molecular Cloning, Characterization, and Expression Analyses
}

\author{
Yang Du ${ }^{1}$, Xiaoqian Tang ${ }^{1}$, Wenbin Zhan ${ }^{1,2}$, Jing Xing ${ }^{1}$ and Xiuzhen Sheng ${ }^{1, *}$ \\ 1 Laboratory of Pathology and Immunology of Aquatic Animals, KLM, Ocean University of China, \\ 5 Yushan Road, Qingdao 266003, China; duyang0422@sina.com (Y.D.); tangxq@ouc.edu.cn (X.T.); \\ wbzhan@ouc.edu.cn (W.Z.); xingjing@ouc.edu.cn (J.X.) \\ 2 Function Laboratory for Marine Fisheries Science and Food Production Processes, Qingdao National \\ Laboratory for Marine Science and Technology, No. 1 Wenhai Road, Aoshanwei Town, Jimo, \\ Qingdao 266071, China \\ * Correspondence: xzsheng@ouc.edu.cn; Tel.: +86-532-8203-2284 \\ Academic Editor: Li Lin \\ Received: 22 July 2016; Accepted: 12 September 2016; Published: 17 September 2016
}

\begin{abstract}
Immunoglobulin tau (IgT) is a new teleost immunoglobulin isotype, and its potential function in adaptive immunity is not very clear. In the present study, the membrane-bound and secreted $\operatorname{IgT}(\mathrm{mIgT}$ and $\mathrm{sIgT}$ ) heavy chain genes were cloned for the first time and characterized in flounder (Paralichthys olivaceus), and found the nucleic acid sequence were exactly same in the $\mathrm{C} \tau 1-\mathrm{C} \tau 4$ constant domains of $\mathrm{mIgT}$ and $\operatorname{sIgT}$, but different in variable regions and the $\mathrm{C}$-terminus. The amino acid sequence of mIgT shared higher similarity with Bovichtus diacanthus $(51.2 \%)$ and Dicentrarchus labrax (45.0\%). Amino acid of flounder IgT, $\operatorname{IgM}$, and IgD heavy chain was compared and the highest similarity was found between $\operatorname{IgT} C \tau 1$ and $\operatorname{IgM} C \mu 1(38 \%)$. In healthy flounder, the transcript levels of IgT mRNA were the highest in gill, spleen, and liver, and higher in peripheral blood leucocytes, skin, and hindgut. After infection and vaccination with Edwardsiella tarda via intraperitoneal injection and immersion, the qRT-PCR analysis demonstrated that the IgT mRNA level was significantly upregulated in all tested tissues, with similar dynamic tendency that increased firstly and then decreased, and higher in gill, skin, hindgut, liver, and stomach in immersion than in the injection group, but no significant difference existed in spleen and head kidney between immersion and injection groups. These results revealed that IgT responses could be simultaneously induced in both mucosal and systemic tissues after infection/vaccination via injection and immersion route, but IgT might play a more important role in mucosal immunity than in systemic immunity.
\end{abstract}

Keywords: tau immunoglobulin (IgT); flounder (Paralichthys olivaceus); gene cloning; expression dynamic; mucosal immunity

\section{Introduction}

Immunoglobulins (Igs) are humoral mediators produced by B lymphocytes playing a key role in the adaptive immune system of jawed vertebrates to protect the organisms from a wide variety of pathogens. There are two forms of Igs (secreted and membrane-bound form), the soluble Igs exist in body fluids involving in humoral immunity and membrane Igs are antigen receptors of B lymphocyte. Each molecule of Ig is composed of two heavy $(\mathrm{H})$ chains and two light $(\mathrm{L})$ chains, and each chain has a variable region at the $\mathrm{N}$-terminus and one or more constant regions at the $\mathrm{C}$-terminus. The $\mathrm{N}$-terminal regions of both $\mathrm{H}$ and $\mathrm{L}$ chains are antigen specificity binding sites, while C-terminal regions determine the functional activities and classes of Igs [1-3]. H and L chains are encoded by the IgH locus and IgL locus, respectively, wherein translocon configuration and multiple gene segments 
are mainly responsible for antibody diversity in the IgH locus. The IgH genes' repertoire is generated by random rearrangement of variable $(\mathrm{VH})$, diversity $(\mathrm{DH})$, and joining $(\mathrm{JH})$ gene segments. Moreover, different constant region genes $(\mathrm{CH})$ selectively perform different effector functions.

According to the amino acid composition and antigenic differences, five IgH isotypes have been identified in mammals: $\operatorname{IgM}$ ( $\mu$ chain), $\operatorname{IgD}(\delta$ chain), $\operatorname{IgG}(\gamma$ chain), $\operatorname{IgA}(\alpha$ chain), and $\operatorname{IgE}(\varepsilon$ chain). In teleost fish only three isotypes are known to date: $\operatorname{IgM}$, the main antibody presents in the serum, can also be secreted into the skin mucus via the polymeric immunoglobulin receptor (pIgR) [4,5]; IgD, perhaps plays a role in the surveillance and immune response regulation in the fish immune system, and the immune response exhibits certain organization specificity [6,7]; IgT/IgZ (for Trout/Zebrafish), found only in teleosts and thought to be an immunoglobulin specialized in mucosal immunity [8], as observed in the gut, skin, and gill mucus of trout $[9,10]$. It has been shown IgT exists in serum as monomers and in gut mucus as multimers, similar to the tetrameric IgM [9]. Fish IgM, D, and T/Z classes refer to the protein products of the isotypes $\mu, \delta$, and $\zeta / \tau$, respectively, which correspond to their associated constant genes. The structure of IgM is highly conserved across species, but IgD and IgT presents diversity. IgD usually contains seven or more $\mathrm{CH}$ domains [11]. The basic structure of the $\zeta / \tau$ gene is not conserved, with species-specific variations across teleosts that the $C \zeta / \tau$ genes are inserted between VH and DJ genes in zebrafish (Danio rerio), fugu (Fugu rubripes), and three-spined stickleback (Gasterosteus aculeatus) [12-14], whereas it is located within the VH gene region in rainbow trout (Oncorhynchus mykiss) and Atlantic salmon (Salmo salar) [15].

A diversity of the domain number of IgT has been seen among species; there are four constant domains in O. mykiss and D. rerio IgT/Z [12,15], three constant domains in G. aculeatus IgT [13,16], two domains in F. rubripes IgZ which corresponding to the first and fourth constant domain of $D$. rerio IgZ, respectively [17]. Carp (Cyprinus carpio) and grass carp (Ctenopharyngodon idellus) own a similar chimeric variant molecule IgM-IgZ, which consists of the $C \mu 1$ domain and a second domain with the highest similarity to $C \zeta 4$ of $D$. rerio [14]. The genome sequence of $C$. idellus IgM-IgZ contains two constant zone exons and two membrane exons, which indicates $\operatorname{IgM}-\operatorname{IgZ}$ is not composed of $\operatorname{IgM}$ and IgZ at the transcription level, but engomphosised at the time of the gene rearrangement. Another new IgZ variant, named IgZ2, has been identified in C. idellus and C. carpio, which is similar to $D$. rerio IgZ2 [18]. It is interesting to note that these two IgZ variants have different functions, IgZ1 is mainly expressed in systemic tissues against blood pathogens, and the IgZ2 chimera is preferentially expressed in the mucosal compartment to respond to parasite infections [19,20].

In recent years, it has been found that a wide divergence of the $\operatorname{IgH}$ chain loci organization exists among teleosts with more and more genomics data excavated [21]. D. rerio IgH locus owns its DH and $\mathrm{JH}$ gene segments and the $\mathrm{C} \tau$ exon is located upstream of $\mathrm{C} \mu$ and $\mathrm{C} \delta$ exons, in analogy to the mouse $\mathrm{T}$ cell receptor $\alpha / \delta$ locus [12]. The canonical structure of $O$. mykiss IgH locus is very similar to that of D. rerio [15]. The Atlantic salmon (S. salar) possesses two parallel IgH isoloci (IGH-A and IGH-B) that can be attributed to its tetraploid past [22]. In addition, Cypriniformes have different types of IgH loci and the two C. carpio IgZ sub-isotypes are encoded by two distinct loci [23]. In fugu IgH loci are similarly found upstream of $C \mu$ and $C \delta$ genes and this Ig isotype has its own D and JH segments, but the gene organization differs significantly from $D$. rerio IgZ [17]. In G. aculeatus IgH locus $C \tau, C \mu$, and $\mathrm{C} \delta$ exons have been found tandem-duplicated three times and separated by $\mathrm{VH}, \mathrm{DH}$, and $\mathrm{JH}$ segments. Additionally, a fourth $C \tau$ gene exists at the $3^{\prime}$ end of the locus $[13,18]$. It is reported that there exist four Ig constant domains constituted in Thunnus orientalis IgM and IgT, and three VH gene families are both shared by IgM and IgT among the four VH gene segment families, while another one is solely used by IgM. Moreover, both IgM and IgT use the same DH segment, whereas the JH gene segments are isotype specific [24].

Although IgT has been cloned and characterized at the gene level in a number of bony fish species in the last several years, the biological functions of $\operatorname{IgT}$ are not well elucidated [25]. Previous reports demonstrate rainbow trout IgT may play an important role in gut and gill mucosal immunity $[9,26]$, and a similar point is supported by Megalobrama amblycephala and Trematomus bernacchii [27,28]. Recently 
it has been found the mucosal adaptive immunity of teleost fish has important roles against aquatic infectious agents; therefore, the study of mucosal immunoglobulins has become an overarching concern. In flounder (Paralichthys olivaceus), the existence of tetrameric IgM in the skin mucus has been well documented [4], whereas the IgT gene of P. olivaceus has not been conducted, and no information on the function of flounder IgT is available.

P. olivaceus is an economically important species in aquaculture industry in China, however, serious diseases, such as bacterial hemorrhagic septicemia caused by Edwardsiella tarda infection, have greatly hindered flounder aquaculture [29]. To date, only limited information on the biological function of the innate immune genes of P. olivaceus is available [30]. In the present study, the IgT gene of $P$. olivaceus was cloned and characterized, and the distribution of IgT mRNA was detected in a series of tissues (peripheral blood leucocytes, gill, skin, spleen, head kidney, trunk kidney, liver, hindgut, muscle, and stomach) of healthy flounder by real-time reverse transcription PCR (RT-PCR). In order to investigate the biological function of IgT of P. olivaceus, the fish was challenged and immunized with live and inactivated $E$. tarda by injection and immersion routes, and the mRNA levels of IgT were determined by quantitative reverse transcription-PCR (qRT-PCR). These data should shed further light on our understanding of the function of IgT in fish adaptive immunity, especially in mucosal immunity, and provide new insights into the vaccine design and vaccination methods in fish aquaculture.

\section{Results}

\subsection{Molecular Characterization of Flounder IgT}

The full-length cDNA of membrane and secreted form of IgT from flounder were obtained by the rapid amplifications of cDNA ends (RACE) method and submitted to NCBI. The complete sequence of membrane IgT cDNA (mIgT GenBank accession number KX174301) was of 2047 bp, containing an open reading frame (ORF) of $1797 \mathrm{bp}$, a 5' UTR of $32 \mathrm{bp}$, and a $3^{\prime}$ UTR of $215 \mathrm{bp}$ with a putative atypical polyadenylation signal sequence AATTAAA located upstream of the poly (A) tail. The deduced mIgT amino acid sequence encoded a single-spanning transmembrane protein of 599 amino acid residues, which possessed a 21-amino acid signal peptide, an extracellular region, a transmembrane region (TM), and a 51-amino acid intracellular region. The molecular weight of flounder mIgT was $66.61 \mathrm{kDa}$ and $\mathrm{pI}=6.99$, and four $\mathrm{N}$-glycosylation residues on the extracellular region were predicted (Figure 1A). While the secreted IgT cDNA (sIgT GenBank accession nr. KX174302) was composed of 1916 bp, containing an ORF of 1656 bp encoding 552 amino acid residues, and the molecular weight was $60.94 \mathrm{kDa}$ and $\mathrm{pI}=7.75$ (Figure 1B).

\subsection{Multiple Sequence Alignment and Phylogenetic Analysis}

The online BLAST analysis showed that the deduced amino acid sequence of $\operatorname{IgT}(\mathrm{mIgT}$ and $\operatorname{sg} \mathrm{T})$ heavy chain of $P$. olivaceus was constituted by one VH and four Ig-like constant domains (CH1, CH2, $\mathrm{CH} 3, \mathrm{CH} 4)$ (Figure 1). Clustal W multiple alignments of flounder IgT revealed that the four constant domains $(\mathrm{C} \tau 1-\mathrm{C} \tau 4)$ corresponded to other reported teleost $\operatorname{IgT} / \mathrm{Z}$, and nucleic acid sequences of $\mathrm{mIgT}$ and sIgT were exactly the same in the $\mathrm{C} \tau 1-\mathrm{C} \tau 4$ constant domains, but different in $\mathrm{VH}$ and $\mathrm{C}$-terminus that mIgT contained a C-terminal TM and sIgT owned a short secreted peptide. In addition to the two conserved cysteine and tryptophan residues in $\mathrm{VH}$ region and all the $\mathrm{CH}$ domains, an extra conserved cysteine residue consisted in $\mathrm{CH} 1$ and two additional cysteine residues presented in $\mathrm{CH} 3$, as well as an additional conserved cysteine residue existed in the C-terminal region of mIgT and sIgT. Four putative $\mathrm{N}$-linked glycosylation sites, i.e. two in $\mathrm{CH} 1$, one in $\mathrm{CH} 3$ and one in $\mathrm{CH} 4$, were found in $\mathrm{IgT}$ of P. olivaceus (Figure 2). Protein sequence analysis showed that flounder $\mathrm{mIgT}$ presented $51.2 \%$ similarity with Bovichtus diacanthus, $45.0 \%$ with D. labrax, $41.4 \%$ with $S$. salar, $40.0 \%$ with T. orientalis, $38.7 \%$ with Epinephelus coioides, $36.6 \%$ with L. sanguineus, $35.6 \%$ with O. mykiss, $25.4 \%$ with D. rerio, $25.3 \%$ with Plecoglossus altivelis, $22.5 \%$ with Ctenopharyngodon idella, 18.1\% with M. amblycephala and $17.2 \%$ with T. rubripes (Figure 3). In the constructed phylogenetic tree, the homologous IgM of the teleosts grouped 
together, $\operatorname{IgD}$ clustered together, while $\operatorname{IgT} / Z$ clustered together, and $\operatorname{IgT}$ of B. diacanthus, L. sanguineus and E. coioides grouped together with P. olivaceus (Figure 3).

\section{A. Membrane-bound $\operatorname{Ig} T$}

AAAACCACCAACCAGACGTTCAACACACGTCCATGATGATTTTAACTAAATGCGCAACATTTCTGCTGCTGTCAGCCATTTCTGGTGTGT M $M$ M I I L TCAGTCAGACTCTGACTGAGTCTGAACCGGCGGTAAAGCGGCACGGAGAATCCCACAAACTGACCTGTACATATGCAGGGATATCTGACG

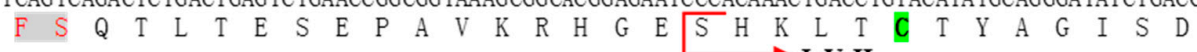
$\rightarrow$ IgV-H

81 ACACTGCTGGTATCAGCTGGATCAGACAAGCTGAAGGAAAAGGCCTGGAGTGGGTTGCCCAAATTTCTGCTCCAAAAGGCGACAACAAAT

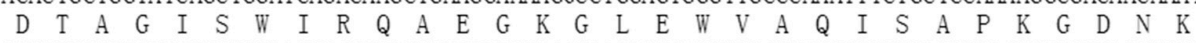
ATTATTCAGCATTTGTCCAGAATCGATTTACAATTTCCAGAAACAACGACATGGACCAGGTGTATCTGCACATGAGCAGCTTGACGAGTG $\begin{array}{llllllllllllllllllllllllllllll}Y & Y & S & A & F & V & Q & N & R & F & T & I & S & R & N & N & D & M & D & Q & V & Y & L & H & M & S & S & L & T & S\end{array}$ AAGACGCCGCTGTTTATTATTGTGCCCGACGGGATCGCGAGGGGTGGCTCGACTACTGGGGCAGTGGGACTGAAGTCACAGTAACATCAG $\begin{array}{lllllllllllllllllllllllllllll}E & D & A & A & V & Y & Y & C & A & R & R & D & R & E & G & W & L & D & Y & W & G & S & G & T & E & V & T & V & T\end{array}$ GAGCGGTTGCATCACCGACTCTGTTCCCTTTGGTTCAGTGCAAACCTGAGGCTGAAGATAGGATCACTGTTGGTTGTCTTGCACACAACT $\begin{array}{llllllllllllllllllllllllllllll}G & A & V & A & S & P & T & L & F & P & L & V & Q & C & K & P & E & A & E & D & R & I & T & V & G & C & L & A & H & \underline{N}\end{array}$ $\longrightarrow$ CH1

TCTCCCCAAAGAGTATTACTTTCCAGTGGACTGATGACAGTGGCAACACCGTGGCCTCGGAACAATATCCTCCAAGTCAGACTGACAGCA $\begin{array}{llllllllllllllllllllllllllllll}F & S & P & K & S & I & T & F & Q & W & T & D & D & S & G & N & T & V & A & S & E & Q & Y & P & P & S & Q & T & D & S\end{array}$ AATACACAGGAGTCAGTTTGGTCAAAGTATCAAAATCTGACTGGGAGTCAATGAAGTCTTTTAATTGTTCAGTAACTCATGCCGGATCTC K Y T G V S L V K V V S K S CCAAAATCCTGCAAGTACAAAGGATTCTTCCTCCAAAAGTGACTTTGCTATCGGTGCCAAGTGAGGACACCCAGGCCCTGGTCTGTACAA

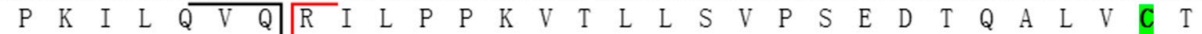
$\stackrel{\mathrm{CH} 2}{\longrightarrow}$

TTGAGGACAGACGCATAGGAACACTTCAATCATTTAAATGGAAAAAGAATGGCGCAGTTCTGAACGACTACATCCACACATCAATGCTAA $\begin{array}{llllllllllllllllllllllllllllll}I & E & D & R & R & I & G & T & L & Q & S & F & K & W & K & K & N & G & A & V & L & N & D & Y & I & H & T & S & M & L\end{array}$ AGATTGGAGAGTTATATTCAGCCATCAGTGTCCTGAAGGTCACAAACACAGACTGGGACAGCAAAGCGGTTTACACCTGTGAGGCAACTT

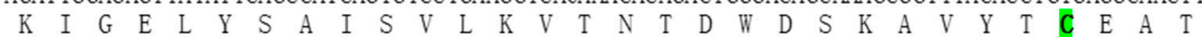
ACGGAGGAAAACCATATATCAAAAAGACCTCTAAAGCTCCTATCACAGTGACACTGAACCAACCAAGTGCTAAAAGGATTTTCAGTGACA

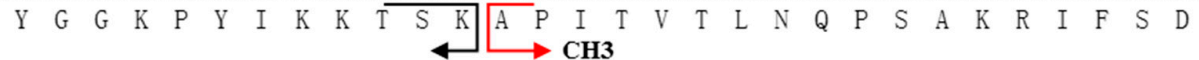
ACCAGGCAGAGCTGAACTGTGTCATCACTGGACAAGACAAGACCATAGTGAATGCAACTAAAATCACATGGCAAATTGATGACAAAAATG

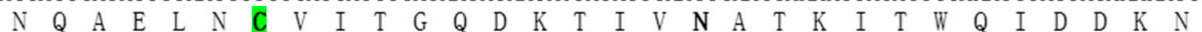
TCCCCTGCGAGA TCACTGAAAAGACAGAGTCTGGAGGCAGTCAGCACAGCAAÄATTAGCAGGATGACTTGTAGCTACGCTGTGTGGCAGA $\begin{array}{llllllllllllllllllllllllllllll}V & P & C & E & I & T & E & K & T & E & S & G & G & S & Q & H & S & K & I & S & R & M & T & C & S & Y & A & V & W & Q\end{array}$ GTGCCAACAAGGTGCGCTGCTCTGCCTCTAGAAAAGATGTGACACCAGTCATTCAAGATCTGGCTGTCTTGAAAGGAGATGGGAGACAGC

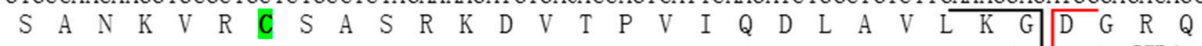
C CH4 $\begin{array}{lllllllllllllllllllllllllllll}P & T & V & T & V & H & L & L & P & G & E & D & I & E & K & K & Q & D & S & E & A & V & T & M & M & C & L & V & S\end{array}$ CTGTGCTGCAGGATTACTACATCGCCTGGTCAGAACATGTTGGACAACAGTCTGGCAACTACGTTGATGGCATCAACTTCCCCCCACAGA $\begin{array}{llllllllllllllllllllllllllllll}P & V & L & Q & D & Y & Y & I & A & W & S & E & H & V & G & Q & Q & S & G & N & Y & V & D & G & I & N & F & P & P & Q\end{array}$ AGACACAGCATGGTTACTCTGTTACAAGCGTTTACACCACCACCAAGAGAAAGTGGGACCTGTACATGTTCAACTGCAACGTCTGGCCTG

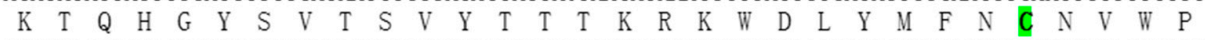
CTGGCAGCAATAATTCCATGACACCACGGGGAGTGTCTAAGGATATTCCCCCAGATTCAAAACTGAATTTTGTCCTGAGCTGCACAGAAG $\begin{array}{llllllllllllllllllllllllllllll}A & G & S & N & N & S & M & T & P & R & G & V & S & K & D & I & P & P & D & S & K & L & N & F & V & L & S & C & T & E\end{array}$ ATGCCATTGAÄGAGGATGAATTCAGCAGTCTGTGGTCCACAACCTCCTCCTTCATATTTCTCTTCATATCCTCTTTTTTCTATAACATGA

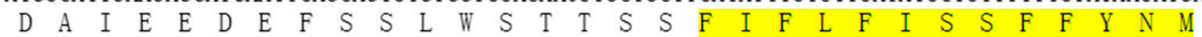
TATTCAGCCTGGTCAAGATGAAGCAACAATAGAGGATGATATAGAGACAGCACAGACGACTTAACATTTTTTTAATCTACCTTTGAAAGT $\begin{array}{lllllllllllllllllllll}I & F & S & L & V & K & M & K & Q & Q & *\end{array}$

1 GTATATGAGGAATAATGTGTTTAACCTGTATGTATGCTAAATTAAAATGTCGCGATATATAACGATTAACTGTCATGGGAAATGGATTTT TTTGTAACC TGTAGAAAALATT AAHCTT TTATGATCAGAAAAAAAAAAAAAAAAAAAAAAAAAAAAA

\section{B. Secretory tail of secreted IgT}

\section{GGTATGGGTTACGCCCTTGAATGTAAATAGTTGATAGCAGCTTTAACTCGTGTGCTAAAATGTTGTTCTGTCTCTGTGTGTGTACTCCCT 555 G M G Y A L E C K * \\ 1759 GCCATGGAAATCTGTGCACTTGTGGTGTCATTGATCTTTGTGATTGTACAAATAAGAGTCAATTTTGTTTTGTTTGTCCTCATTCTGTGI 1849 TTGTGACATTGTGTGTTGTGTGTTGACCGTTTTAAATAA-TGTTGCATGCAAAAAAAAAAAAAAAAAAAAAAA}

Figure 1. (A) Nucleotide and deduced amino acid sequences of the flounder membrane-bound IgT (mIgT, GenBank accession number KX174301). The sequence was divided into $\mathrm{VH}$ and four $\mathrm{CH}$ domains on the basis of sequence comparisons with the IgH chains of other teleosts. The cysteines (C) were denoted by green bold. The atypical polyadenylation signal (AATTAAA) in the 3'-UTR was shaded in red grey. The signal peptide sequence used hotlink and grey shadow. The four Ig like domains were shown in red arrows for the upstream and dark arrows for the downstream of each domain. The transmembrane region was shaded in yellow grey. Four putative $N$-glycosylation residues were marked with black bold and underline; (B) Nucleotide and deduced amino acid sequences of secreted tail part of the flounder secreted IgT (sIgT, GenBank accession number KX174302). The atypical polyadenylation signal (AATAAA) in the $3^{\prime}$-UTR was shaded in red grey. 

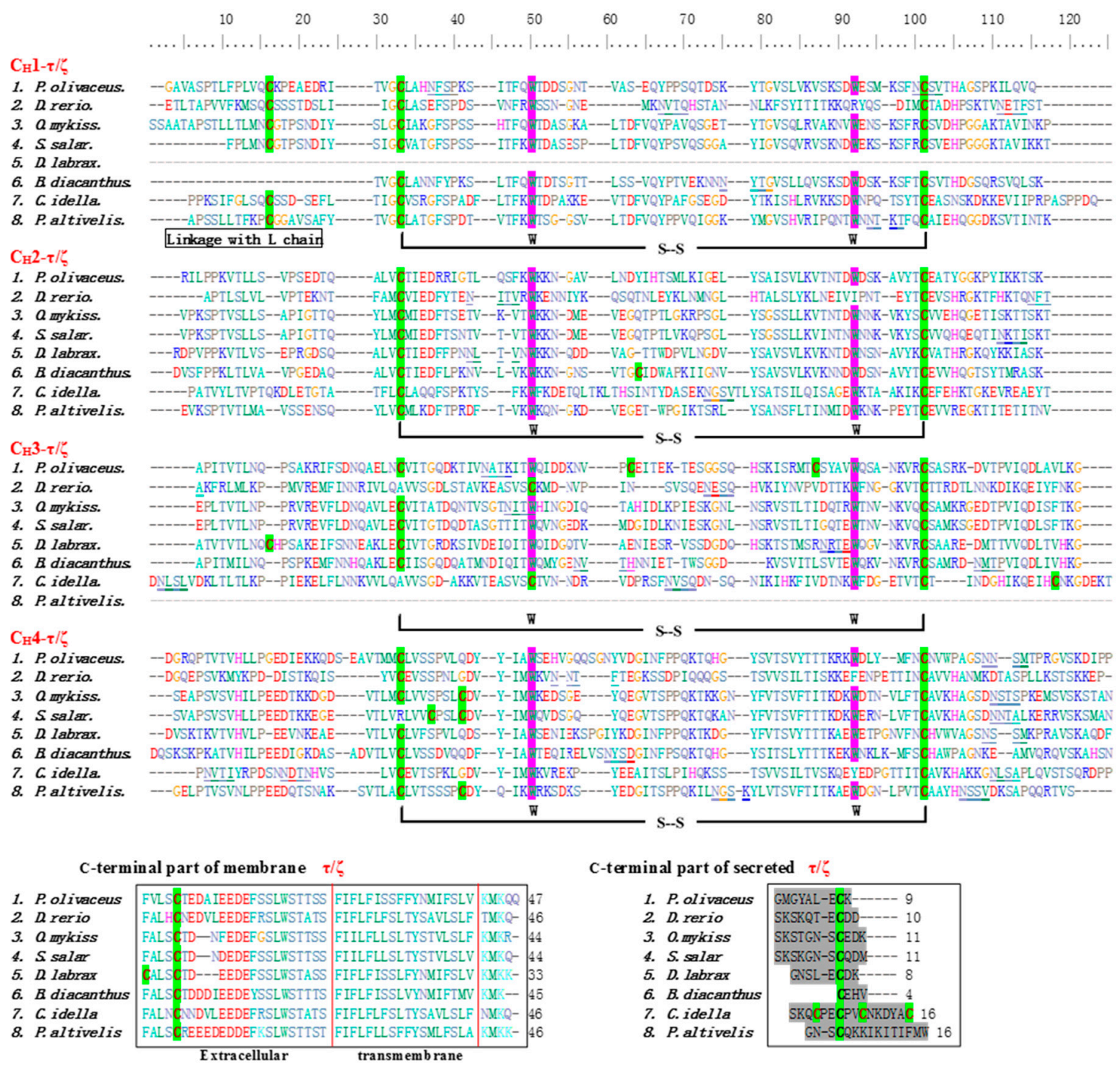

Figure 2. Alignment of translated $\operatorname{IgT} / \operatorname{IgZ}$ sequences in different fish species. The first alignment showed immunoglobulin constant domain $(\mathrm{CH} 4-\tau / \zeta-\mathrm{CH} 4-\tau / \zeta)$ and a segment encoding the membrane proximal extracellular part, the transmembrane peptide, and a short cysteine tail. Cysteine and tryptophan residues were shaded green bold and purple bold, and underlined font putative predicted $N$-glycosylation sites were in black bold, respectively. In the second part of the alignment, the C-terminal part of the secreted IgT, which was encoded by the $\mathrm{CH} 4$ exon, the letters was shown in the gray shading. GenBank accession numbers for membrane and secreted forms of $\operatorname{IgT} / \mathrm{Z}$ sequences were displayed: Paralichthys olivaceus: KX174301, KX174302; Danio rerio: AAT67444.1, AAT67446.1; Oncorhynchus mykiss: AAW66980.1, AAW66981.1; Salmo salar: ACX50290.1, ACX50293.1; Dicentrarchus labrax: AKK32392.1, AKK32388.1; Bovichtus diacanthus: AKA09866.1, AKA09828.1; Ctenopharyngodon idella: ABY76180.1, ADD82655.1; Plecoglossus altivelis: BAP75402.1, BAP75403.1. 


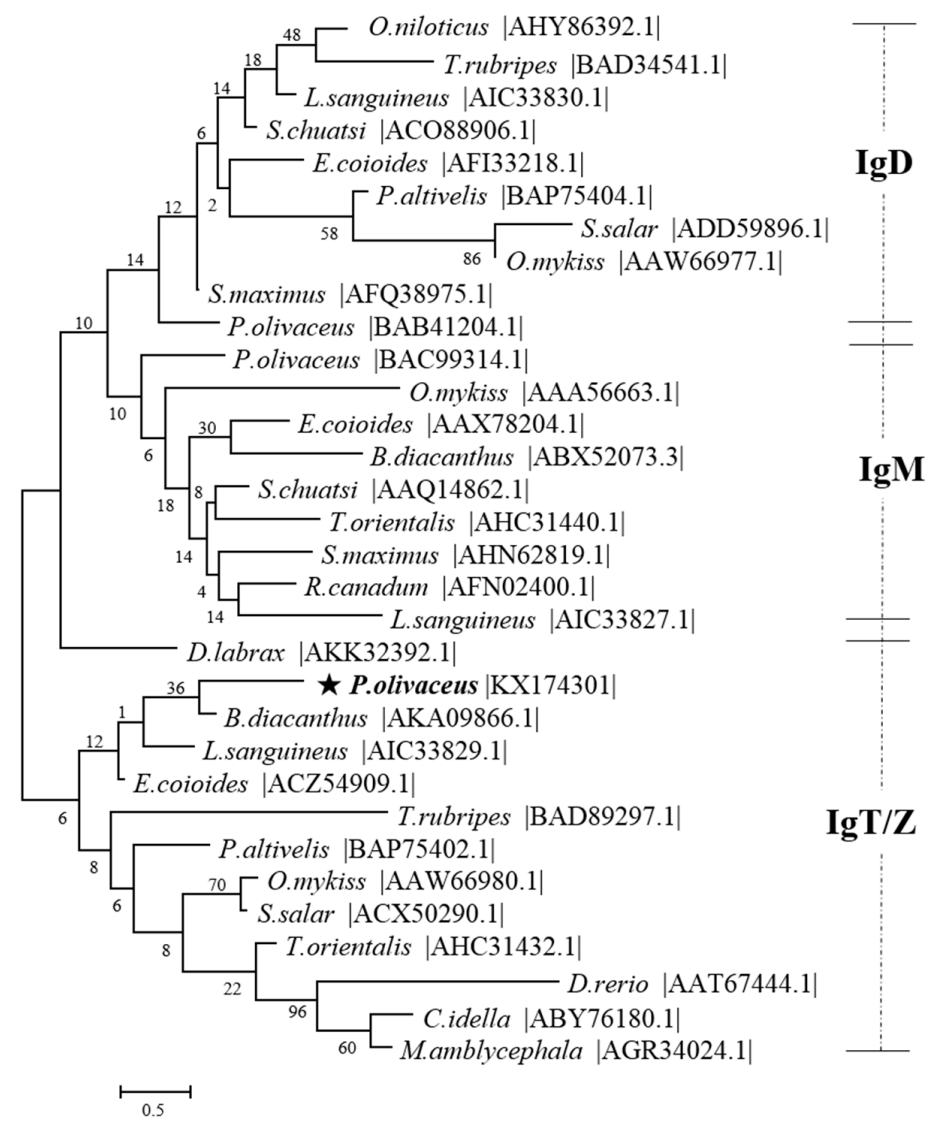

Figure 3. Phylogenetic tree analysis of IgT family members from flounder and other fish species. The five-pointed star highlighted the position of $P$. olivaceus. The tree was constructed by the "neighbor-joining" method using MEGA 5.0 software. Node values represented the percent of bootstrap confidence derived from 1000 replicates. The accession number for each sequence followed the common species name.

As shown in Table 1, the amino acid sequence identity matrix of constant regions and the single constant domains of IgT/Z heavy chain among the different fish species mentioned in Figure 2 were displayed. The constant regions of P. olivaceus IgT had the highest similarity to B. diacanthus $(52 \%)$, followed by O. mykiss (43\%), S. salar (42.1\%) and D. labrax (42.2\%). Higher similarity in IgT C $\tau 1$ domain was observed between P. olivaceus and B. diacanthus (48.9\%), O. mykiss $(43.1 \%)$ and S. salar (43\%). For IgT C $\tau 2$ domain, P. olivaceus showed higher similarity to B. diacanthus (52\%) and D. labrax (51\%), and then O. mykiss (40.6\%) and S. salar (36.4\%). As compared to the IgT C $\tau 3$ domain of P. olivaceus with other fish, the similarity was higher in D. labrax (55.1\%) and B. diacanthus (52.8\%), next in O. mykiss (42.4\%), and S. salar (43.3\%). Moreover, the IgT C $\tau 4$ domain of P. olivaceus also shared high similarity to that of D. labrax (57\%) and B. diacanthus (55.6\%), followed by O. mykiss $(45.6 \%)$ and S. salar $(43.9 \%)$. In the phylogenetic tree constructed, the homologous $C_{H} 1-\tau / \zeta, C_{H} 2-\tau / \zeta, C_{H} 3-\tau / \zeta$, and $C_{H} 4-\tau / \zeta$ clustered together, respectively (Figure 4). In P. olivaceus, $\operatorname{IgT} C \tau 1$ maintained a higher similarity to $C \tau 2(19.1 \%)$ and the $C \tau 2$ domain showed higher similarity to $C \tau 3$ (16\%). Compared IgT C $\tau$ with IgM $\mathrm{C} \mu$ and IgD C $\delta$ domains in P. olivaceus, the deduced amino acid sequence of IgT C $\tau 1$ showed highest similarity with that of IgM C $\mu 1$ (38\%), followed by IgT C $\tau 2$ (19.1\%), and IgD C $\delta 2(18.2 \%)$ and C $\delta 7$ (17.6\%); IgT C $\tau 2$ domain displayed higher similarity with $\operatorname{IgMC} \mathrm{C} 1$ (24.7\%) and $\mathrm{C} \mu 2(19.2 \%)$; While IgT $\mathrm{C} \tau 3$ domain showed higher similarity with $\operatorname{IgD} \mathrm{C} \delta 6(16 \%)$ than other domains and $\operatorname{IgT} \mathrm{C} \tau 4$ domains showed highest similarity with IgD C 87 (16.8\%) (Table 2). 
Table 1. Amino acid sequence identity matrix of constant regions and the single constant domains of IgT/Z heavy chain between the different fish species reported in Figure 2 .

\begin{tabular}{|c|c|c|c|c|c|c|c|}
\hline 1. P. olivaceus & 2. D. rerio & 3. O. mykiss & 4. S. salar & 5. D. labrax & 6. B. diacanthus & 7. C. idella & 8. P. altivelis \\
\hline \multicolumn{8}{|l|}{ Constant regions (CH1-CH4) } \\
\hline 1. P. olivaceus & $\bullet 22.3$ & $\bullet 43$ & $\bullet 42.1$ & $\bullet 42.2$ & $\cdot 52$ & $\bullet 23.5$ & $\bullet 25.4$ \\
\hline 2. D. rerio & & $\bullet 24.5$ & $\bullet 23.2$ & $\bullet 17.9$ & $\bullet 19.3$ & $\cdot 36.3$ & $\bullet 17.6$ \\
\hline 3. O. mykiss & & & $\bullet 79.8$ & $\bullet 31.6$ & $\bullet 39$ & $\bullet 27.5$ & $\bullet 34.1$ \\
\hline 4. S. salar & & & & $\bullet 33.1$ & $\bullet 39.5$ & $\bullet 26.2$ & $\cdot 33$ \\
\hline 5. D. labrax & & & & & $\bullet 44.3$ & $\bullet 17.3$ & $\bullet 17.7$ \\
\hline 6. B. diacanthus & & & & & & $\bullet 21.5$ & $\bullet 25.8$ \\
\hline 7. C. idella & & & & & & & $\bullet 20.5$ \\
\hline 8. P. altivelis & & & & & & & \\
\hline \multicolumn{8}{|l|}{$\mathrm{C}_{\mathrm{H} 1-\tau / \zeta}$} \\
\hline 1. P. olivaceus & $\bullet 23.2$ & .43 .1 & $\bullet 43.0$ & & $\bullet 48.9$ & $\bullet 28.0$ & $\bullet 35.0$ \\
\hline 2. D. rerio & & $\bullet 16.6$ & $\bullet 17.0$ & & $\bullet 17.3$ & $\bullet 18.8$ & $\bullet 20.2$ \\
\hline 3. O. mykiss & & & $\bullet 79.8$ & & $\bullet 37.2$ & $\bullet 34.8$ & $\bullet 48.0$ \\
\hline 4. S. salar & & & & & $\cdot 39.1$ & .36 .5 & .47 .4 \\
\hline 5. D. labrax & & & & & & & \\
\hline 6. B. diacanthus & & & & & & $\bullet 27.1$ & $\bullet 31.9$ \\
\hline 7. C. idella & & & & & & & $\bullet 32.6$ \\
\hline 8. P. altivelis & & & & & & & \\
\hline \multicolumn{8}{|l|}{$\mathrm{C}_{\mathrm{H}} 2-\tau / \zeta$} \\
\hline 1. P. olivaceus & $\bullet 23.7$ & $\bullet 40.6$ & $\bullet 36.4$ & .51 .0 & .52 .0 & $\bullet 23.1$ & $\cdot 34.3$ \\
\hline 2. D. rerio & & $\bullet 35.4$ & $\bullet 34.3$ & $\bullet 27.8$ & $\bullet 28.8$ & $\bullet 16.1$ & $\bullet 31.2$ \\
\hline 3. O. mykiss & & & $\bullet 88.4$ & $\bullet 42.7$ & .38 .5 & $\bullet 19.4$ & $\bullet 42.1$ \\
\hline 4. S. salar & & & & $\bullet 42.7$ & $\cdot 36.4$ & $\bullet 17.5$ & .41 .0 \\
\hline 5. D. labrax & & & & & .58 .9 & $\bullet 19.4$ & $\cdot 34.3$ \\
\hline 6. B. diacanthus & & & & & & $\bullet 20.3$ & $\bullet 38.5$ \\
\hline 7. C. idella & & & & & & & $\bullet 20.3$ \\
\hline 8. P. altivelis & & & & & & & \\
\hline \multicolumn{8}{|l|}{$\mathrm{C}_{\mathrm{H}} 3-\tau / \zeta$} \\
\hline 1. P. olivaceus & $\bullet 21.6$ & $\bullet 42.4$ & $\bullet 43.3$ & $\bullet 55.1$ & .52 .8 & $\bullet 18.1$ & \\
\hline 2. D. rerio & & $\bullet 22.6$ & $\bullet 20.7$ & $\bullet 23.3$ & $\bullet 19.8$ & $\bullet 47.8$ & \\
\hline 3. O. mykiss & & & $\bullet 83.9$ & $\bullet 37.9$ & .40 .5 & $\bullet 21.5$ & \\
\hline 4. S. salar & & & & $\bullet 39.8$ & $\bullet 44.3$ & $\bullet 22.4$ & \\
\hline 5. D. labrax & & & & & .54 .2 & $\bullet 18.6$ & \\
\hline 6. B. diacanthus & & & & & & $\bullet 15.5$ & \\
\hline 7. C. idella & & & & & & & \\
\hline 8. P. altivelis & & & & & & & \\
\hline
\end{tabular}


Table 1. Cont

\begin{tabular}{|c|c|c|c|c|c|c|c|c|}
\hline & 1. P. olivaceus & 2. D. rerio & 3. O. mykiss & 4. S. salar & 5. D. labrax & 6. B. diacanthus & 7. C. idella & 8. P. altivelis \\
\hline \multicolumn{9}{|l|}{$\mathrm{C}_{\mathrm{H}} 4-\tau / \zeta$} \\
\hline 1. P. olivaceus & & $\bullet 26.7$ & $\bullet 45.6$ & $\bullet 43.9$ & .57 .0 & .55 .6 & $\bullet 24.1$ & $\bullet 36.7$ \\
\hline 2. D. rerio & & & $\bullet 30.6$ & $\bullet 27.9$ & $\bullet 25.6$ & $\bullet 17.7$ & $\cdot 52.3$ & $\bullet 23.2$ \\
\hline 3. O. mykiss & & & & $\bullet 78.7$ & $\bullet 45.6$ & $\cdot 39.3$ & .33 .6 & .46 .3 \\
\hline 4. S. salar & & & & & .45 .6 & $\bullet 37.6$ & $\bullet 31.8$ & .43 .6 \\
\hline 5. D. labrax & & & & & & .51 .3 & $\bullet 26.3$ & .33 .6 \\
\hline 6. B. diacanthus & & & & & & & $\bullet 19.4$ & $\bullet 32.2$ \\
\hline 7. C. idella & & & & & & & & $\bullet 30.3$ \\
\hline 8. P. altivelis & & & & & & & & \\
\hline
\end{tabular}

Amino acid sequence identities with decreasing degree were indicated by four icon sets $\bullet \bullet \bullet \bullet$.

Table 2. Amino acid sequence identity matrix of the single constant domains of $\operatorname{IgT}(\mathrm{KX} 174301, \tau 1-\tau 4), \operatorname{IgM}(\mathrm{AB} 052744, \mu 1-\mu 4)$ and IgD (AB052658, $\delta 1-\delta 7)$ heavy chain in Paralichthys olivaceus.

\begin{tabular}{|c|c|c|c|c|c|c|c|c|c|c|c|c|c|c|c|}
\hline & $\tau 1$ & $\tau 2$ & $\tau 3$ & $\tau 4$ & $\mu \mathbf{1}$ & $\mu 2$ & $\mu 3$ & $\mu 4$ & $\delta 1$ & $\delta 2$ & $\delta 3$ & $\delta 4$ & $\delta 5$ & $\delta 6$ & $\delta 7$ \\
\hline$\tau 1$ & & $\bullet 19.1$ & $\bullet 12.0$ & $\bullet 13.2$ & $\bullet 38.0$ & $\bullet 14.7$ & $\bullet 11.9$ & $\bullet 12.6$ & $\bullet 13.2$ & •18.2 & $\bullet 10.1$ & $\bullet 15.2$ & $\bullet 11.9$ & $\bullet 13.7$ & $\bullet 17.6$ \\
\hline$\tau 2$ & & & -16.0 & $\bullet 14.0$ & 24.7 & •19.2 & $\bullet 8.10$ & $\bullet 13.3$ & -21.6 & $\bullet 12.3$ & $\bullet 8.30$ & $\bullet 13.5$ & $\bullet 11.8$ & •15.7 & •16.6 \\
\hline$\tau 3$ & & & & $\bullet 12.9$ & $\bullet 11.1$ & $\bullet 13.5$ & $\bullet 12.7$ & $\bullet 10.7$ & $\bullet 11.1$ & $\bullet 13.0$ & $\bullet 12.7$ & $\bullet 12.3$ & $\bullet 14.2$ & -16.0 & $\bullet 14.8$ \\
\hline$\tau 4$ & & & & & $\bullet 13.2$ & $\bullet 9.20$ & •13.9 & $\bullet 12.8$ & $\bullet 8.80$ & $\bullet 10.6$ & $\bullet 9.50$ & •14.1 & $\bullet 14.7$ & $\bullet 14.2$ & $\bullet 16.8$ \\
\hline$\mu 1$ & & & & & & •15.6 & •12.8 & $\bullet 13.4$ & •16.0 & •19.2 & •16.6 & $\bullet 15.2$ & $\bullet 14.6$ & •15.5 & $\bullet 14.7$ \\
\hline$\mu 2$ & & & & & & & $\bullet 9.20$ & •10.6 & $\bullet 14.6$ & $\bullet 10.2$ & $\bullet 11.9$ & $\bullet 14.1$ & $\bullet 11.7$ & $\bullet 11.3$ & •13.1 \\
\hline$\mu 3$ & & & & & & & & •13.8 & $\bullet 10.0$ & $\bullet 15.2$ & $\bullet 11.2$ & $\bullet 12.2$ & •13.7 & •12.5 & •11.9 \\
\hline$\mu 4$ & & & & & & & & & •13.2 & •14.0 & -12.4 & $\bullet 15.0$ & 18.4 & •20.0 & $\bullet 15.0$ \\
\hline$\delta 1$ & & & & & & & & & & •14.1 & •12.8 & •15.0 & •12.8 & •18.3 & •17.9 \\
\hline$\delta 2$ & & & & & & & & & & & $\bullet 10.2$ & •11.5 & 17.4 & $\bullet 9.00$ & •11.5 \\
\hline$\delta 3$ & & & & & & & & & & & & -16.3 & $\bullet 14.6$ & $\bullet 13.6$ & •10.3 \\
\hline$\delta 4$ & & & & & & & & & & & & & $\bullet 13.7$ & •19.6 & •17.4 \\
\hline$\delta 5$ & & & & & & & & & & & & & & •16.0 & $\bullet 14.6$ \\
\hline$\delta 6$ & & & & & & & & & & & & & & & -16.6 \\
\hline$\delta 7$ & & & & & & & & & & & & & & & \\
\hline
\end{tabular}

Amino acid sequence identities with decreasing degree were indicated by four icon sets $\bullet \bullet \bullet \bullet$ 


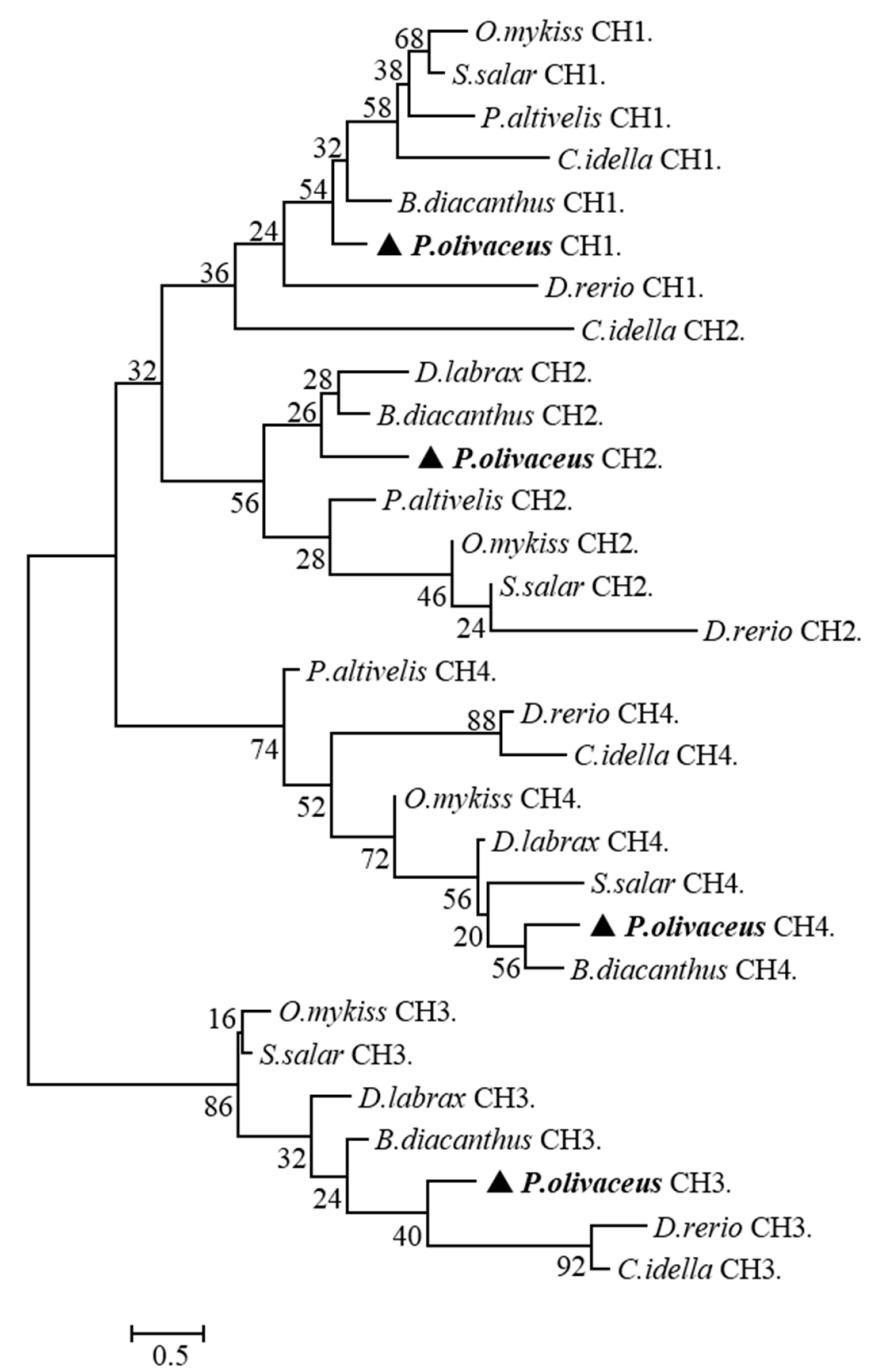

Figure 4. Phylogenetic tree of the single heavy chain constant domains of IgT/Z from eight teleost species reported in Figure 2. The triangle highlighted the position of P. olivaceus.

\subsection{Tissue Distribution of IgT Transcript in Healthy Flounder}

The expression of IgT mRNA was found in all tested tissues of flounder (Figure 5). The results showed that IgT expression was detected at the highest level in gill, spleen, and liver, and higher levels in peripheral blood leukocyte, skin, and hindgut, followed by stomach, head kidney, trunk kidney, midgut, and foregut, but much lower in muscle and heart.

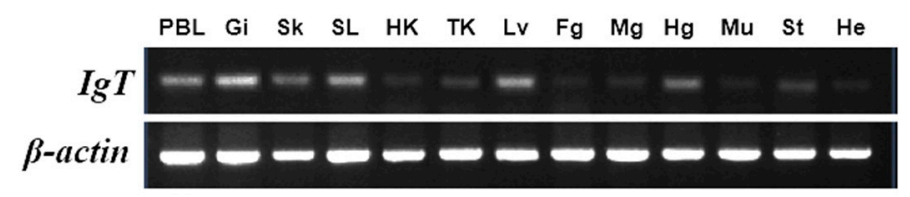

Figure 5. Tissue distribution pattern of IgT mRNA transcripts in healthy flounder. The gene expression profiles of IgT in thirteen tissues were determined by RT-PCR analysis. Individual tissues from three fish were equally pooled for RNA purification. Total RNA from three flounder $(n=3)$ were isolated and subjected to DNase I treatment and then transcribed into cDNA. $\beta$-Actin of flounder was employed as an internal reference gene. PBL: peripheral blood leucocytes; Gi: gill; Sk: skin; SL: spleen; HK: head kidney; TK: trunk kidney; Li: liver; Fg: foregut; Mg: midgut; Hg: hindgut; Mu: muscle; St: stomach; He: heart. 

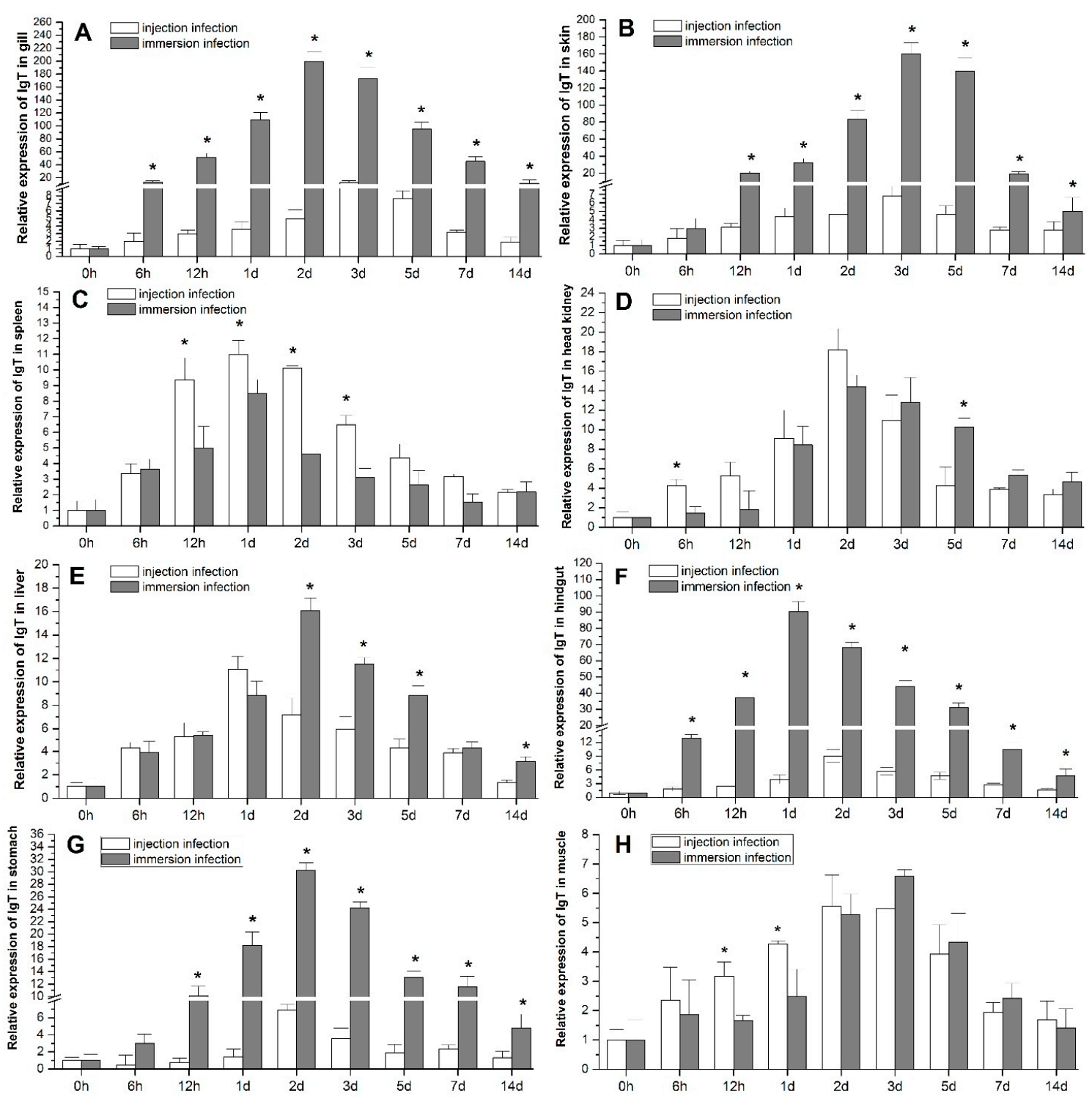

Figure 6. The gene expression profiles of IgT in different tissues ((A): gill, (B): skin, (C): spleen, (D): head kidney, $(\mathbf{E})$ : liver, $(\mathbf{F})$ : hindgut, $(\mathbf{G})$ : stomach, $(\mathbf{H})$ : muscle) of flounder were determined by qRT-PCR analysis post-infection by intraperitoneal (IP) injection with live E. tarda bacteria $\left(0.2 \mathrm{~mL} ; 1.0 \times 10^{7} \mathrm{CFU} / \mathrm{mL}\right.$ per fish $)$ and immersion $\left(1.0 \times 10^{8} \mathrm{CFU} / \mathrm{mL}\right.$ bath for $\left.60 \mathrm{~min}\right)$, respectively. Individual tissue from three fish was equally pooled for RNA purification. 18sRNA of flounder was employed as an internal reference gene. Values were presented as means \pm standard deviation $(n=3)$, and the asterisk $\left(^{*}\right)$ indicated the significant differences $(p<0.05)$ between IP injection group and immersion group at the each time points after infection.

\subsection{Tissue Expression of IgT Post Bacterial Challenge}

The results of qRT-PCR examination showed that the expression of IgT transcript increased significantly in the eight tissues tested in the bacteria-challenged groups compared with the blank control and the expression level before challenge $(0 \mathrm{~h})$ (Figure 6), while the expression of $\operatorname{IgT}$ in the negative control had no significant difference from that of the blank control during experiment (the results not shown). The expression of IgT mRNA was significantly up-regulated post $E$. tarda infection by immersion and IP injection, and showed a tendency to increase firstly and then to recover to blank control level after 14 days, with a peak at 1-3 days post infection (p.i.). The up-regulation of IgT expression was significantly higher in the immersion group than the injection group from $6 \mathrm{~h}$ p.i. in gill 
(Figure 6A), skin (Figure 6B), hindgut (Figure 6F) and stomach (Figure 6G), and from 2 days p.i. in liver (Figure 6A). While in spleen (Figure 6C), the up-regulation of IgT in immersion group was significantly lower than injection group from $12 \mathrm{~h}$ p.i. Compared with the control, the peak values of IgT expression was 199-fold in gill, 159-fold in skin, 90-fold in hindgut, 30-fold in stomach, 16-fold in liver, 14-fold in head kidney, eight-fold in spleen, and 6.5-fold in muscle in immersion group; and 18-fold in head kidney, 12-fold in gill, 11-fold in spleen and liver, nine-fold in hindgut, 6.8-fold in stomach, six-fold in skin, and 5.5-fold in muscle in injection group, respectively (Figure 6A-H). Changes in peak expression of $\operatorname{IgT}$ in immersion group, in contrast to injection group, were most dramatic in skin (26-fold, three days p.i.), gill (16.7-fold, $2-3$ days p.i.) and hindgut (10-fold, one day p.i.), followed by stomach (4.2-fold, two days p.i.), and then liver (1.45-fold, $1-2$ days p.i.) and muscle (1.2-fold, $2-3$ days p.i.), however, lower in spleen (0.72-fold, one day p.i.) and head kidney (0.78-fold, two days p.i.).

\subsection{Expression of IgT after Inactivated E. tarda Immunization}

The qRT-PCR results showed that IgT mRNA expressions were up-regulated significantly compared to the blank control in all tested tissues after IP injection and immersion immunization with formalin-killed E. tarda (Figure 7), displaying a similar tendency that first increased and then decreased. However, the expression levels were down to the blank control level (at 14 days p.i.) earlier in injection than in immersion group. The up-regulations of IgT expression were significantly higher in gill (Figure 7A), skin (Figure 7B), liver (Figure 7E), hindgut (Figure 7F), and stomach (Figure 7G) in immersion group than injection group from $6 \mathrm{~h}$ to 14 days, and reached peak earlier in gill and skin (2-3 days) than in liver, hindgut, and stomach (5-7 days), whereas in spleen, head kidney, and muscle (Figure 7C,D,H), the two immunization routes induced similar dynamic changes of IgT expression, and the peak time appeared at 5-7 days. Compared with the control, The peak value of IgT expression was 80.2-fold in gill, 58.5-fold in skin, 38.2-fold in hindgut, 32.3-fold in liver, 25.7-fold in stomach, 12.4-fold in spleen, 5.6-fold in head kidney, and 5.2-fold in muscle in the immersion group; and 12.6-fold in liver, 10.5-fold in spleen, 8.7-fold in stomach, 7.5-fold in skin, 5.8-fold in gill, 5.7-fold in head kidney, 5.5-fold in muscle, and 5.1-fold in hindgut in the injection group, respectively (Figure 7A-H). The peak expression of IgT in immersion group, in contrast to injection group, were most dramatic in gill (13.8-fold), skin (7.7-fold), and hindgut (7.6-fold), followed by stomach (2.8-fold) and liver (2.5-fold), but no significant difference existed in spleen (1.2-fold), head kidney (0.89-fold), and muscle (0.94-fold) between the two immunization groups.
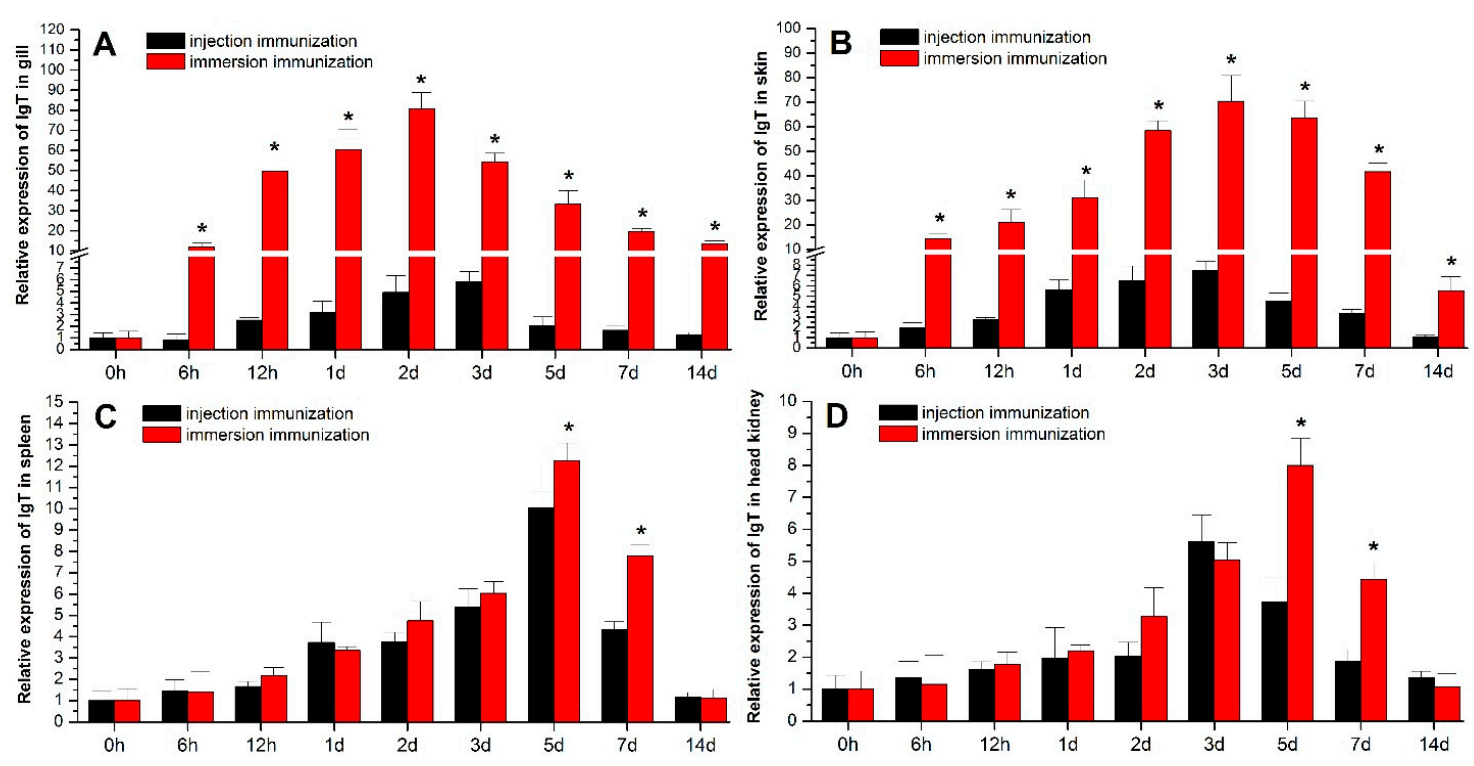

Figure 7. Cont. 

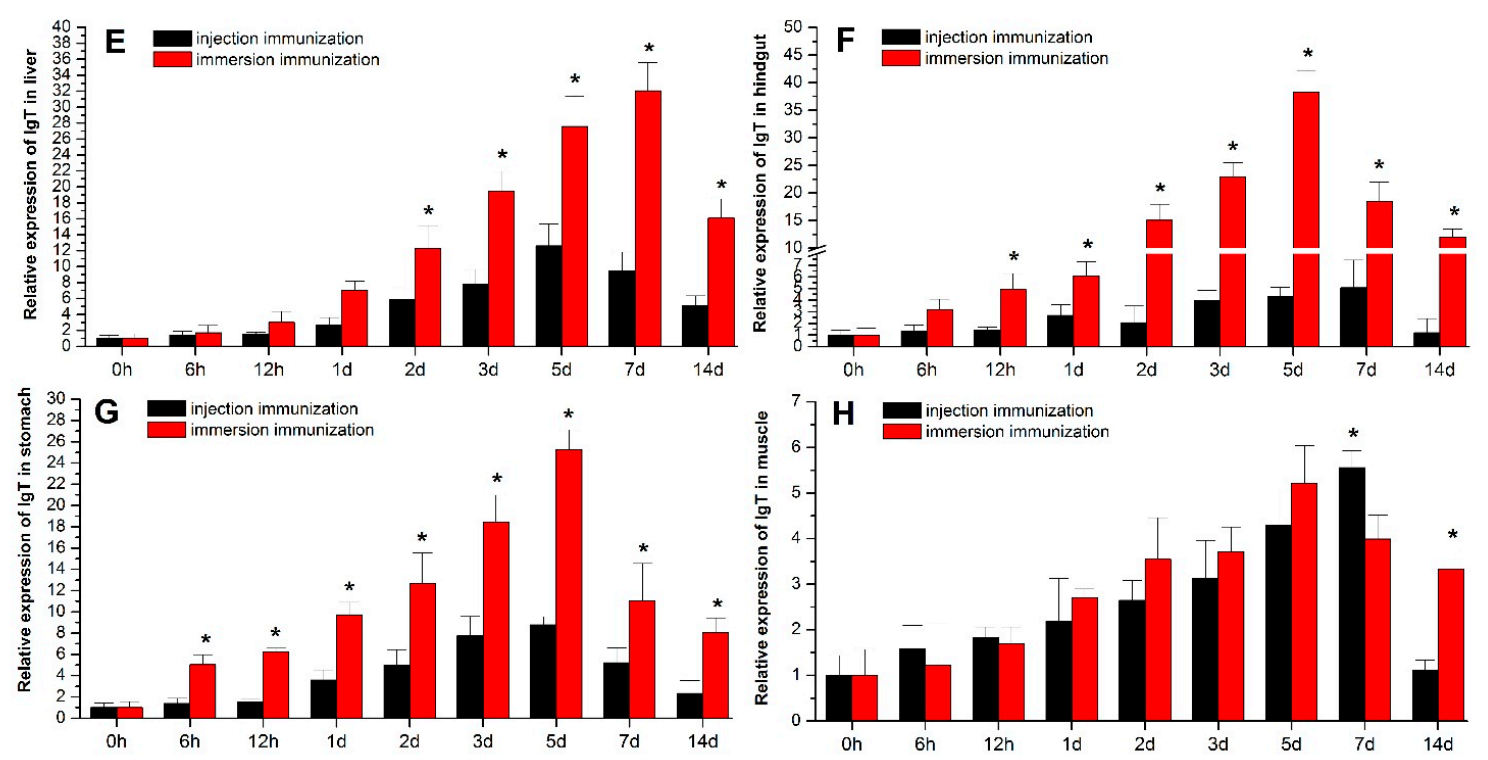

Figure 7. The dynamic changes of IgT mRNA transcripts expression in different tissues ((A): gill, (B): skin, (C): spleen, (D): head kidney, (E): liver, (F): hindgut, (G): stomach, (H): muscle) of flounder were determined by qRT-PCR assay post-immunization by IP injection with formalin-killed $E$. tarda bacteria $\left(0.2 \mathrm{~mL} ; 1.0 \times 10^{8} \mathrm{CFU} / \mathrm{mL}\right.$ per fish $)$ and bath immersion $\left(1.0 \times 10^{8} \mathrm{CFU} / \mathrm{mL}\right.$ for $\left.60 \mathrm{~min}\right)$, respectively. Individual tissues from three fish were equally pooled for RNA purification. 18sRNA of flounder was employed as an internal reference gene. The identities of all PCR products were confirmed by sequencing. Values were presented as means \pm standard deviation $(n=3)$, and the asterisk $\left(^{*}\right)$ indicated the significant differences $(p<0.05)$ between IP injection group and immersion group at each time points after immunization.

\section{Discussion}

The immunoglobulin of teleost fish has important immunological roles against aquatic infectious agents. Recent studies indicate that IgM is the principal immunoglobulin involved in humoral immunity and the primordial mucosal $\mathrm{Ig}$, IgD potentially performs a unique role in vertebrate immune responses, and IgT acts as a specialized mucosal Ig in bony fish [6,31-35]. The existence and biological functions of IgM and IgD has been well documented in P. olivaceus [36,37], but IgT has not been reported. The present study reported for the first time the membrane-bound and secreted forms of IgT genes encoding the heavy chain constant region in P. olivaceus, characterized the nucleotide and protein sequence, and analyzed its tissue distribution in healthy fish, also firstly demonstrated the immune response pattern in the process of infection and immunization by E. tarda, and determined its functions in the systemic and mucosal immunity of flounder.

Sequence analysis revealed that the primary and secondary structure of the flounder $\mathrm{mIgT}$ shared a high degree of sequence similarity and phylogenetic relationship to the $\mathrm{mIgT} / \mathrm{Z}$ of other teleost fish, presenting $51.2 \%$ similarity with $B$. diacanthus, $45.0 \%$ with $D$. labrax, $41.4 \%$ with $S$. salar, $40.0 \%$ with $T$. orientalis, $38.7 \%$ with E. coioides, $36.6 \%$ with L. sanguineus, $35.6 \%$ with O. mykiss, and $25.4 \%$ with D. rerio. It is reported that there exists great variation in the structure of the IgT heavy chain gene among fish species, and the IgT heavy chain of most fish consists of $\mathrm{VH}, \mathrm{DJ}$ area, and two to four Ig tau constant domains $[8,13,16]$. The present study found that the prototypic gene structure of the flounder IgT (mIgT and sIgT) consisted of one $\mathrm{VH}$, four Ig-like constant domains ( $\mathrm{CH} 1, \mathrm{CH} 2, \mathrm{CH} 3$, and $\mathrm{CH} 4)$, and a C-terminus, which corresponded to IgT of trout [8], and the nucleic acid sequences of $\mathrm{mIgT}$ and $\operatorname{sIgT}$ were exactly the same in the $\mathrm{C} \tau 1-\mathrm{C} \tau 4$ constant domains, but different in the $\mathrm{VH}$ and $\mathrm{C}$-terminus, the mIgT heavy chain constant region was followed by a TM and sIgT followed by a short secreted peptide. The difference in gene structure between $\mathrm{mIgT}$ and sIgT might indicate their different functions in the immune response, and more research on their biological features is needed. Moreover, each Ig-like 
constant area of flounder IgT contained two cysteine and tryptophan conservative sites, which might be involved in the formation of disulfide bonds and play a decisive role in the formation and maintenance of the immunoglobulin spatial structure [38]. Additionally, an extra conserved cysteine residue in CH1 might play an important role in connecting the $\mathrm{H}$ chain to $\mathrm{L}$ chain, and two additional cysteine residues in $\mathrm{CH} 3$ might assist in connecting the $\mathrm{H}$ chain to another $\mathrm{H}$ chain or forming a polymer structure. Generally, some transcription regulatory elements localized in $5^{\prime}$-UTR could influence the translation of gene expression, the sequence of $5^{\prime}$-UTR were short in the present sequences, similar to sIgZ of M. amblycephala (KC894946), which might indicate some motif in the $5^{\prime}$-UTR that provided a link between transcription and post-transcriptional stages of IgT/Z gene expression; another possibility was that the $5^{\prime}$-UTR sequence nonspecifically combined with the adapter primer during the first-strand cDNA reverse transcription of RACE [27,39]. 3'-UTR usually plays a vital role of mediation and stabilization in most genes' translation, and the sequences are highly diverse [40,41]. It is worth noting that the $3^{\prime}$-UTR sequences of flounder mIgT/sIgT were short with an integrity poly (A) tail, similar to L. sanguineus (KF728201.1), E. coioides IgZ (GU182366.1), and T. bernacchii IgT (KP876587), and the full-length have been verified correct, demonstrating there would be no unspecific priming during the PCR. Furthermore, it was reported that the average length of $3^{\prime}$-UTR sequences increased during evolution and their utilization associated to organism complexity [42], thus, we speculated that there existed species specificity in the $3^{\prime}$-UTR sequence of $\operatorname{IgT} / Z$.

The constant regions ( $\mathrm{CH} 1-\mathrm{CH} 4)$ of P. olivaceus IgT showed the highest similarity with B. diacanthus (52\%), followed by O. mykiss (43\%), S. salar $(42.1 \%)$, and D. labrax (42.2\%). Interestingly, a similar identity was observed as compared single P. olivaceus IgT C $\tau 1, C \tau 2, C \tau 3$, and $C \tau 4$ domains with other fish species, which suggested an equivalent evolution extent among each $C \tau$ domain of $P$. olivaceus. The domains of $\operatorname{IgM}(\mathrm{AB} 052744, \mu 1-\mu 4)$ and $\operatorname{IgD}(\mathrm{AB} 052658, \delta 1-\delta 7)$ heavy chain of P. olivaceus were analyzed by Srisapoome et al [37], but the amino acid similarity among each domain of $\operatorname{IgM}$, IgD, and IgT was not compared. In the present study, domain by domain comparison of IgT $(\tau 1-\tau 4)$, $\operatorname{IgM}(\mu 1-\mu 4)$ and $\operatorname{IgD}(\delta 1-\delta 7)$ heavy chain was performed and displayed that the amino acid identity was highest between $\operatorname{IgT} C \tau 1$ and $\operatorname{IgM} C \mu 1(38 \%)$, followed by $\operatorname{IgT} C \tau 2$ and $\operatorname{IgM} C \mu 1(24.7 \%)$, then decreased gradually between other single constant domains, and the data indicated that $\mathrm{C} \tau 3$ and $\mathrm{C} \tau 4$ provided the specificity to the IgT isotype in flounder. Relatively lower similarity between IgD C $\delta$ domains and $\operatorname{IgM} C \mu$, IgT $C \tau$ was observed, which might suggest that the evolution level of $\operatorname{IgD}$ was different from IgM and IgT, and forebode difference of biological function among them [38].

The expression and distribution patterns of IgT have certain tissue specificity, but still exhibit considerable variation in different fish species. The zebrafish IgZ was mainly expressed in lymphoid organs, including thymus [12]. IgT mRNA levels are higher in the spleen, head kidney, trunk kidney, and gill in P. altivelis [43]. A gene similar IgT in fugu and mandarin (Siniperca chuatsi) fish was expressed in head kidney, spleen, and gill $[17,33]$. In trout and salmon, IgT displayed similar expression in various tissues, especially in spleen and head kidney $[15,44]$. The present study showed that the IgT expression was highest in gill, spleen and liver, and higher in leukocyte, skin, and hindgut, followed by stomach, head kidney, trunk kidney, midgut, and foregut, and lower in the stomach and muscle in healthy flounder. The spleen and head kidney of bony fishes are predominant systemic immune organs, which are functionally and morphologically similar to the bone marrow of mammals [45]. It is verified that the gill, skin, hindgut and liver are important mucosa-associated lymphoid tissues of teleosts which are abundant with immune cells such as B and T cells, macrophages and granulocytes [46]. Therefore, the higher expression of IgT in these systemic and mucosal immune tissues in flounder suggested that IgT might play a vital role in the systemic and mucosal immunity.

The administration of intraperitoneal injection infection or vaccination mostly induced a fish systemic immune response, whereas the immersion rout is always thought to activate the mucosal immune response by the mucosal tissues, such as gill, skin, and hindgut [47-49]. In order to determine the role of flounder IgT in the systemic and mucosal immune regulation, the fish were infected and vaccinated with live and inactivated $E$. tarda by intraperitoneal injection and immersion, respectively, 
and the results showed that the IgT mRNA level was up-regulated significantly in all tested tissues, with similar dynamic tendency that increased firstly and then decreased, which revealed that IgT could participate in the immune response of flounder against bacterial pathogens, and both injection and immersion infection/immunization routes all could simultaneously induce systemic and mucosal immune responses. A good example was shown in rainbow trout that the IgT was not only involved in mucosal immunity, but also in systemic immunity [9,50]. Furthermore, the up-regulation of IgT in gill, skin, liver, hindgut, and stomach were obviously higher in immersion than injection groups after infection and vaccination, indicating that IgT might play more important role in the mucosal immune than systemic immune in flounder. On the other hand, no significant difference in IgT up-regulation expression was found in spleen and head kidney between immersion and injection group, suggesting that both immersion and injection routes could induce similar IgT response in systemic immune organs of flounder.

In flounder, IgM has been verified to play important roles in the mucosal immunity. We have previously developed the monoclonal antibodies $(\mathrm{McAb})$ of anti-serum IgM and anti-mucus IgM of flounder, and found that the IgM antibody levels in serum and mucus increased post-immunization in flounder [51-54]. Moreover, a secreted component-like molecule (SC) of pIgR that mediated Igs secretions was detected in skin mucus of flounder using the polyclonal antibodies against pIgR, suggesting flounder IgM involved in mucosal immunity [5]. Therefore, further research to illuminate the biological function and transport mechanism of IgT and the functional relationship of IgT and IgM in mucosal immunity in P. olivaceus are needed.

In conclusion, the membrane-bound and secreted forms of $\operatorname{IgT}$ in flounder were cloned and its expression analyses were performed in this study. The IgT mRNA level was up-regulated after E. tarda infection and vaccination via the IP injection and immersion routes, and the up-regulation of IgT was significantly higher in gill, skin, liver, hindgut, and stomach in immersion than injection group, but similar in spleen and head kidney in both immersion and injection groups. These results suggested that this unique IgT could participate in the immune response of flounder against bacterial pathogens in systemic and mucosal tissues simultaneously, but might play more important roles in mucosal immunity than systemic immunity. To our knowledge, this was the first study which revealed the immune response pattern of IgT in flounder after infection/vaccination via injection and immersion routes, which are of potential importance for the immunological control of fish disease. More importantly, these results have crucial implications for the future design of fish vaccines that stimulate systemic, as well as mucosal, immunity. However, more research on the flounder IgT in the protein expression level are needed in the future.

\section{Materials and Methods}

\subsection{Ethics Statement}

This study was carried out strictly in line with the procedures in the Guide for the Use of Experimental Animals of the Ocean University of China. In this study, for the methods used in animal experiments were approved by the Institutional Animal Care and Use Committee of Ocean University of China (Permit Number: 20150101). All efforts were dedicated to minimize suffering.

\subsection{Fish}

Healthy flounder (average length: 15-17 cm) were obtained from a fish farm in Shandong Province, Rizhao, China. The fish were kept in quarantined plastic tanks with a follow-through water volume of $500 \mathrm{~L}$ (dissolved oxygen $6.0 \pm 0.5 \mathrm{mg} \cdot \mathrm{L}^{-1}$; temperature $20 \pm 1{ }^{\circ} \mathrm{C}$ ) and fed with commercial diet twice daily. All fish were acclimatized for two weeks prior to treatment. 


\subsection{Cloning of the Full-Length IgT}

Three apparently healthy flounder were sampled, and the gill, spleen, head kidney, and hindgut were isolated immediately after anesthetization with MS-222, frozen in liquid nitrogen and stored at $-80{ }^{\circ} \mathrm{C}$ prior to use. The tissue was immediately homogenized in TRIzol Reagent (Invitrogen, CarIsbad, CA, USA), and total RNA was extracted using the E.Z.N.A. HP Total RNA Kit (Omega Bio-Tek, Norcross, GA, USA) and reverse-transcripted into first-strand cDNA using SuperScript Reverse Transcriptase according to the manufacturer's instructions. By performing a homology search of the common flounder genome using the O. mykiss (AAW66980.1) with BLAST [55], IgT-like sequences were obtained. For the isolation of the flounder IgT cDNA fragment, multiple alignments of the amino acid sequences of several other fish were performed using the DNAMAN multiple sequence alignments program. Degenerate primers were designed based on the highly conserved sequences of T. orientalis (KF713336.1), Lutjanus sanguineus (KF728201.1), and Dicentrarchus labrax (KP096356.1). A flounder IgT partial gene sequence was cloned using degenerate primers IgT-F/IgT-R from the common flounder cDNA template. PCR amplification was performed under the following conditions: one cycle of $94{ }^{\circ} \mathrm{C}$ for $5 \mathrm{~min}, 35$ cycles of $94{ }^{\circ} \mathrm{C}$ for $30 \mathrm{~s}, 56^{\circ} \mathrm{C}$ for $30 \mathrm{~s}$, and $72{ }^{\circ} \mathrm{C}$ for $50 \mathrm{~s}$, and a final extension of $72{ }^{\circ} \mathrm{C}$ for $10 \mathrm{~min}$. The PCR products were gel-extracted and ligated into the pMD-18T vector. Following transformation into competent Escherichia coli DH5 $\alpha$ cells, positive clones were screened by Ampicilin selection and colony PCR and sequenced by Shanghai BioSune Biotechnology Co., Ltd. (Shanghai, China).

Subsequently, rapid amplifications of cDNA ends (RACE) were performed using the SMART RACE cDNA amplification Kit (BD Bioscience Clontech Co., Palo Alto, CA, USA) to get the full-length IgT cDNA sequences by the specific primers which were designed based on the obtained partial sequence. For $3^{\prime}$ RACE, the first-strand cDNA was performed as described above with the adapter primer $3^{\prime}$-CDS supplied by the kit. The first round of PCR was performed using the primer pair of IgT $3^{\prime}$-RACE 1st out /UPM (adaptor primer), under the following conditions: one cycle of $94^{\circ} \mathrm{C}$ for $5 \mathrm{~min}$, five cycles of $94{ }^{\circ} \mathrm{C}$ for $30 \mathrm{~s}, 64{ }^{\circ} \mathrm{C}$ for $30 \mathrm{~s}$, and $72{ }^{\circ} \mathrm{C}$ for $2 \mathrm{~min}, 29$ cycles of $94{ }^{\circ} \mathrm{C}$ for $30 \mathrm{~s}, 60^{\circ} \mathrm{C}$ for $30 \mathrm{~s}$, and $72{ }^{\circ} \mathrm{C}$ for $2 \mathrm{~min}$, followed by a final extension of $72{ }^{\circ} \mathrm{C}$ for $10 \mathrm{~min}$. The resultant products were diluted (1:20) and re-amplified in the second round PCR using the primer pair of IgT $3^{\prime}$-RACE nested in /NUP, under the same reaction conditions. For $5^{\prime}$-RACE, the first-strand cDNA was synthesized using oligo $\mathrm{d}(\mathrm{T})$-anchor primer and 5-AP-DG-adapter primer. A primary PCR was accomplished with antisense primer IgT $5^{\prime}$-RACE 1st and sense primer UPM. A nest gene-specific primer IgT $5^{\prime}$-RACE nested and the manufacturer's PCR anchor primer NUP were used to accomplish PCR amplification of the double-stranded cDNA. Amplification cycles were performed as follows: one cycle of $94{ }^{\circ} \mathrm{C}$ for $5 \mathrm{~min}, 35$ cycles of $94{ }^{\circ} \mathrm{C}$ for $30 \mathrm{~s}, 58^{\circ} \mathrm{C}$ for $30 \mathrm{~s}$, and $72{ }^{\circ} \mathrm{C}$ for $2 \mathrm{~min}$, followed by a final extension of $72{ }^{\circ} \mathrm{C}$ for $10 \mathrm{~min}$. All primers used for this cloning process were listed in Table 3.

Table 3. Primers used for gene cloning and qPCR in this study.

\begin{tabular}{ll}
\hline Primer Name & Oligonucleotide Sequence \\
\hline Core segment PCR & 5'-ACAGTGACACTGAAMCMWCCAAGT-3' \\
IgT-F & 5'-GTYACMAGYGTYTWCACCATC-3' \\
IgT-R & \\
\hline RACE PCR & 5'-CCCTACTGACCTTTAAGCCA-3' \\
IgT 3'-RACE 1st & 5'-CGATCACCAATGTTCACTGC-3' \\
IgT 3'-RACE nested & 5'-AGGCAGCACAGGTAACAGGT-3' \\
IgT 5'-RACE 1st & 5'-TTGGTGTGTATGCTGAAAGAT-3' \\
IgT 5'-RACE nested & 5'-AAGCAGTGGTATCAACGCAGAGTAC(T)30VN-3' \\
3'-CDS $^{\prime}$ 5PM & 5'-CTAATACGACTCACTATAGGGCAAGCAGTGGTATCAACGCAGAGT-3' \\
NUP & 5'-AAGCAGTGGTATCAACGCAGAGT-3' \\
5-AP-DG & 5'-AAGCAGTGGTATCAACGCAGAGTACGCGGGGGGGGGG-3' \\
\hline
\end{tabular}


Table 3. Cont.

\begin{tabular}{ll}
\hline Primer Name & Oligonucleotide Sequence \\
\hline Full-length validation & \\
qIgT-F & $5^{\prime}$-CCACCAACCAGACGTTCAAC-3' \\
mIgT-R & $5^{\prime}$-TTGCTTCATCTTGACCAGGC-3' \\
sIgT-R & $5^{\prime}$-GGCGTAACCCATACCCTTAG-3' \\
\hline RT-PCR & \\
IgT1-F & $5^{\prime}$-CGACTCTGTTCCCTTTGGTTC-3' \\
IgT1-R & $5^{\prime}$-GTTTTCCTCCGTAAGTTGCCT-3' \\
\hline qRT-PCR & \\
IgT2-F & $5^{\prime}$-TAATTGTTCAGTAACTCATGCCG-3' \\
IgT2-R & $5^{\prime}$-GATTGAAGTGTTCCTATGCGTCT-3' \\
$\beta$-actin F & $5^{\prime}$-AGAGCAAGAGAGGCATCCTGAC-3' \\
$\beta$-actin R & $5^{\prime}$-CGATGGGTGATGACCTGTCC-3' \\
18sRNA-F & $5^{\prime}$-GGTCTGTGATGCCCTTAGATGTC-3' \\
18sRNA-R & $5^{\prime}$-AGTGGGGTTCAGCGGGTTAC-3' \\
\hline \multicolumn{1}{c}{ RACE, rapid amplification of cDNA ends; Ig, immunoglobulin; qRT, quantitative real time; F, forward; R, reverse. }
\end{tabular}

\subsection{Domain Organization and Sequence Analyses}

The full length of membrane-bound $\operatorname{IgT}(\mathrm{mIgT})$ and secreted $\operatorname{IgT}(\mathrm{sIgT})$ were confirmed by RT-PCR using sequence-specific primers qIgT-F, mIgT-R, and sIgT-R (Table 3). The open reading frames (ORFs) and deduced protein sequences of $\mathrm{mIgT}$ and sIgT were predicted using an ORF Finder program [56], and also by blasting genomic stretches against protein databases at NCBI (blastx). Immunoglobulin domains were predicted by PROSITE database [57]. The trans-membrane domain was predicted using the TMpred program [58], and N-linked glycosylation sites were predicted by the NETNGLYC 1.0 server [59]. The draft genome databases and expressed sequence tag (EST) databases distributed at Swiss-Prot protein databases, Expasy, Ensembl, UCSC Genome Browser and TIGR were employed to retrieve the immunoglobulin molecules. Multiple alignments of sequences were conducted using the Clustal W program (version 1.83) [60]. On the basis of the alignment, phylogenetic trees were constructed with MEGA 5 software using the neighbor-joining method [61]. Statistical significance of each branch was examined by the bootstrap. The veracity of these trees was studied using the bootstrapping method by executing 1000 replicates. The isoelectric point (pI), potential N-glycosylation sites and the molecular weight of the deduced $\operatorname{IgT}$ proteins were calculated by the Expert Protein Analysis System [62].

\subsection{Quantitative Analysis of IgT Expression at the mRNA Level in Healthy Flounder}

The expression of IgT mRNA in tissues of healthy fish, including peripheral blood leucocytes, gill, skin, spleen, head kidney, trunk kidney, liver, foregut, midgut, hindgut, muscle, stomach, and heart, were detected by RT-PCR. Total RNA was extracted from different tissues as described in 2.2 and the RNA concentration and integrity were measured using NanoDrop ND-1000 (NanoDrop Technologies, Wilmington, DE, USA) and by agarose gel electrophoresis. First-strand cDNA was synthesized using a PrimeScript RT reagent kit (Takara, Otsu, Japan) with Oligo dT/random hexamer primers, according to the manufacturer's protocol. cDNA was diluted in diethyl dicarbonate (DEPC)-treated water and stored at $-20^{\circ} \mathrm{C}$. Two gene-specific primers IgT1-F and IgT1-R (Table 3) were used to amplify a $537 \mathrm{bp}$ gene fragment of IgT, and two actin primers $\beta$-ActinF and $\beta$-ActinR (Table 3) were used to amplify $\beta$-actin gene fragment as the internal control for RT-PCR. PCR amplification was performed under the following conditions: one cycle of $94{ }^{\circ} \mathrm{C}$ for $5 \mathrm{~min}, 35$ cycles of $94{ }^{\circ} \mathrm{C}$ for $30 \mathrm{~s}, 56^{\circ} \mathrm{C}$ for $30 \mathrm{~s}$, and $72{ }^{\circ} \mathrm{C}$ for $60 \mathrm{~s}$, followed by a final extension of $72{ }^{\circ} \mathrm{C}$ for $10 \mathrm{~min}$. The PCR products were gel-extracted and pictures were taken. The cloned amplicons were confirmed by sequencing. Primer sequences were given in Table 3. 


\section{6. qRT-PCR Analysis of IgT Expression in Response to Live and Inactivated E. tarda}

Healthy flounder were divided into six experimental groups and transferred into tanks (50 fish/tank) that each contained $500 \mathrm{~L}$ of water. The bacterin of live and inactivated E. tarda was prepared as described previously [54]. Group A was infected by intraperitoneal (IP) injection with live E. tarda $\left(0.2 \mathrm{~mL} ; 1.0 \times 10^{7}\right.$ colony-forming units (CFU) $/ \mathrm{mL}$ in phosphate buffer saline (PBS)); group B was infected by immersion with live $E$. tarda $\left(1.0 \times 10^{8} \mathrm{CFU} / \mathrm{mL}\right)$ for $60 \mathrm{~min}$; group $\mathrm{C}$ was immunized by IP injection with formalin-killed E. tarda $\left(0.2 \mathrm{~mL} ; 1.0 \times 10^{8} \mathrm{CFU} / \mathrm{mL}\right)$; group $\mathrm{D}$ was vaccinated by immersion with formalin-killed E. tarda $\left(1.0 \times 10^{8} \mathrm{CFU} / \mathrm{mL}\right)$ for $60 \mathrm{~min}$; group E was injected with equal dose PBS as negative control; and group F was not treated as blank control. The gill, skin, spleen, head kidney, liver, hindgut, stomach, and muscle were collected from three fish from each group before treatment $(0 \mathrm{~h})$ and at $6 \mathrm{~h}, 12 \mathrm{~h}, 1$ day, 2 days, 3 days, 5 days, 7 days and 14 days post-treatment, immediately transferred to a $-80^{\circ} \mathrm{C}$ freezer, and used to isolate total RNA. Total RNA and cDNA were prepared from tissue samples as previously described in Section 2.4. qRT-PCR was performed using a Roche480 real-time PCR system (LightCycler480, Agilent, Santa Clara, CA, USA). Each qPCR was performed in a total volume of $20 \mu \mathrm{L}$ containing $10 \mu \mathrm{L}$ of SYBR Green I Master, $0.4 \mu \mathrm{L}$ of forward and reverse primers $(10 \mathrm{mM}), 2 \mu \mathrm{L}$ of diluted cDNA and RNase-free water. The thermal cycling profile consisted of an initial denaturation at $95^{\circ} \mathrm{C}$ for $30 \mathrm{~s}$, followed by 45 cycles of denaturation at $95{ }^{\circ} \mathrm{C}$ for $5 \mathrm{~s}$ and annealing/extension at $60^{\circ} \mathrm{C}$ for $30 \mathrm{~s}$. An additional temperature-ramping step was utilized to produce melting curves of the reaction from 65 to $95^{\circ} \mathrm{C}$. The expression level of IgT in blank control individuals was defined as 1 . A $150 \mathrm{bp}$ gene fragment of $\operatorname{IgT}$ was amplified by the specific primers IgT2-F and IgT2-R (Table 3), and two primers 18sRNA-F and 18sRNA-R (Table 3) of flounder were used to amplify 18sRNA gene fragment as the internal control for qRT-PCR. The identities of all the products were confirmed by sequencing.

\subsection{Statistical Analysis}

The qRT-PCR data were analyzed using MX Pro-Mx3000P Multi-plex Quantitative PCR system Software (LightCycler480, Agilent) and the relative expression ratio $(R)$ of mRNA was calculated according to the formula $2^{-\Delta \Delta C t}$ [63]. The data were normalized for each gene against those obtained for 18sRNA [64]. The results were presented as means with standard deviations of fold increase/decrease from three fish at each time point. The transcript level of each Ig gene was compared between different treatment at each time point by one-way ANOVA, and the level of significance was set to $p<0.05$ for all analyses. The statistical software Origin (Version 8.0, OriginLab, Northhampton, MA, USA) was used for creating graphs.

Acknowledgments: This study was supported by the National Natural Science Foundation of China (31472295; 31672685; 31302216), National Basic Research Program of China (2012CB114406), and Taishan Scholar Program of Shandong Province.

Author Contributions: Xiuzhen Sheng and Wenbin Zhan conceived, designed the experiments; Yang Du carried out the experiments; Yang Du, Xiaoqian Tang and Jing Xing participated in data analysis, coordination and manuscript preparation.

Conflicts of Interest: The authors declare no conflict of interest.

\section{References}

1. Porter, R.R. The structure of the heavy chain of immunoglobulin and its relevance to the nature of the antibody-combining site. The second CIBA medal lecture. Biochem. J. 1967, 105, 417-426. [CrossRef] [PubMed]

2. Kabat, E.A.; Wu, T.T. Construction of a three-dimensional model of the polypeptide backbone of the variable region of kappa immunoglobulin light chains. Proc. Natl Acad. Sci. USA 1972, 69, 960-964. [CrossRef] [PubMed] 
3. Kabat, E.A.; Wu, T.T.; Bilofsky, H. Variable region genes for the immunoglobulin framework are assembled from small segments of DNA-a hypothesis. Proc. Natl. Acad. Sci. USA 1978, 75, 2429-2433. [CrossRef] [PubMed]

4. Sheng, X.Z.; Xu, G.J.; Tang, X.Q.; Zhan, W.B. Monoclonal antibodies recognizing mucus immunoglobulin and surface immunoglobulin-positive cells of flounder (Paralichthys olivaceus). Vet. Immunol. Immunopathol. 2012, 145, 143-150. [CrossRef] [PubMed]

5. Xu, G.J.; Zhan, W.B.; Ding, B.J.; Sheng, X.Z. Molecular cloning and expression analysis of polymeric immunoglobulin receptor in flounder (Paralichthys olivaceus). Fish Shellfish Immunol. 2013, 35, 653-660. [CrossRef] [PubMed]

6. Edholm, E.S.; Bengten, E.; Wilson, M. Insights into the function of IgD. Dev. Comp. Immunol. 2011, 35, 1309-1316. [CrossRef] [PubMed]

7. Yi, S.; Wei, Z.G.; Hammarstrom, L.; Zhao, Y.F. The immunoglobulin $\delta$ gene in jawed vertebrates: A comparative overview. Dev. Comp. Immunol. 2011, 35, 975-981.

8. Zhang, Y.A.; Salinas, I.; Sunyer, J.O. Recent findings on the structure and function of teleost IgT. Fish Shellfish Immunol. 2011, 31, 627-634. [CrossRef] [PubMed]

9. Zhang, Y.A.; Salinas, I.; Li, J.; Parra, D.; Bjork, S.; Xu, Z.; LaPatra, S.E.; Bartholomew, J.; Sunyer, J.O. IgT, a primitive immunoglobulin class specialized in mucosal immunity. Nat. Immunol. 2010, 11, 827-835. [CrossRef] [PubMed]

10. Xu, Z.; Gomez, D.; Parra, D.; Takizawa, F.; Sunyer, J.O. IgT plays a prominent role in gill immune response of rainbow trout. Fish Shellfish Immunol. 2013, 34, 1686. [CrossRef]

11. Rouaud, P.; Saintamand, A.; Saad, F.; Carrion, C.; Lecardeur, S.; Cogné, M.; Denizot, Y. Elucidation of the enigmatic IgD class-switch recombination via germline deletion of the $\operatorname{IgH} 3^{\prime}$ regulatory region. J. Exp. Med. 2014, 211, 975-985. [CrossRef] [PubMed]

12. Danilova, N.; Bussmann, J.; Jekosch, K.; Steiner, L.A. The immunoglobulin heavy-chain locus in zebrafish: Identification and expression of a previously unknown isotype, immunoglobulin Z. Nat. Immunol. 2005, 6, 295-302. [CrossRef] [PubMed]

13. Gambón-Deza, F.; Sánchez-Espinel, C. Presence of an unique IgT on the IgH locus in three-spined stickleback fish (Gasterosteus aculeatus) and the very recent generation of a repertoire of VH genes. Dev. Comp. Immunol. 2010, 34, 114-122. [CrossRef] [PubMed]

14. Savan, R.; Aman, A.; Nakao, M.; Watanuki, H.; Sakai, M. Discovery of a novel immunoglobulin heavy chain gene chimera from common carp (Cyprinus carpio L.). Immunogenetics 2005, 57, 458-463. [CrossRef] [PubMed]

15. Hansen, J.D.; Cooper, M.D. Discovery of a unique Ig heavy-chain isotype (IgT) in rainbow trout: Implications for a distinctive B cell developmental pathway in teleost fish. Proc. Natl. Acad. Sci. USA 2005, 102, 6919-6924. [CrossRef] [PubMed]

16. Bao, Y.H.; Wang, T.; Guo, Y.C.; Zhao, Z.H.; Li, N.; Zhao, Y.F. The immunoglobulin gene loci in the teleost Gasterosteus aculeatus. Fish Shellfish Immunol. 2010, 28, 40-48. [CrossRef] [PubMed]

17. Savan, R.; Aman, A.; Sato, K.; Yamaguchi, R.; Sakai, M. Discovery of a new class of immunoglobulin heavy chain from fugu. Eur. J. Immunol. 2005, 35, 3320-3331. [CrossRef] [PubMed]

18. Hu, Y.L.; Xiang, L.X.; Shao, J.Z. Identification and characterization of a novel immunoglobulin $\mathrm{Z}$ isotype in zebrafish: Implications for a distinct B cell receptor in lower vertebrates. Mol. Immunol. 2010, 47, 738-746. [CrossRef] [PubMed]

19. Ryo, S.; Wijdeven, R.H.M.; Tyagi, A.; Hermsen, T.; Kono, T.; Karunasagar, I.; Rombout, J.H.; Sakai, M.; Kemenade, B.M.L.V.; Savan, R. Common carp have two subclasses of bony fish specific antibody $\operatorname{IgZ}$ showing differential expression in response to infection. Dev. Comp. Immunol. 2010, 34, 1183-1190. [CrossRef] [PubMed]

20. Young, M.; Li, E.S.; Branham, E.; Browne, Z.; Koufteros, C.A.; Pham, S.E.; Kim, J.C.; Stebbins, E.A.; Wenck, F.E.; Zhang, A.L.; et al. Investigating distinct immunization routes in zebrafish on mucosal immunity. J. Immunol. 2016, 196, 137-145.

21. Fillatreau, S.; Six, A.; Magadan, S.; Castro, R.; Sunyer, J.O.; Boudinot, P. The astonishing diversity of Ig classes and B cell repertoires in teleost fish. Front. Immunol. 2013, 4, 28. [CrossRef] [PubMed] 
22. Yasuike, M.; de Boer, J.; von Schalburg, K.R.; Cooper, G.A.; McKinnel, L.; Messmer, A.; So, S.; Davidson, W.S.; Koop, B.F. Evolution of duplicated IgH loci in Atlantic salmon, Salmo salar. BMC Genom. 2010, 11, 1. [CrossRef] [PubMed]

23. Henkel, C.V.; Dirks, R.P.; Jansen, H.J.; Forlenza, M.; Wiegertjes, G.F.; Howe, K.; van den Thillart, G.E.E.J.M.; Spaink, H.P. Comparison of the exomes of common carp (Cyprinus carpio) and zebrafish (Danio rerio). Zebrafish 2012, 9, 59-67. [CrossRef] [PubMed]

24. Mashoof, S.; Pohlenz, C.; Chen, P.L.; Deiss, T.C.; Iii, D.G.; Buentello, A.; Criscitiello, M.F. Expressed IgH $\mu$ and $\tau$ transcripts share diversity segment in ranched Thunnus orientalis. Dev. Comp. Immunol. 2014, 43, 76-86. [CrossRef] [PubMed]

25. Rombout, J.H.W.M.; Yang, G.; Kiron, V. Adaptive immune responses at mucosal surfaces of teleost fish. Fish Shellfish Immunol. 2014, 40, 634-643. [CrossRef] [PubMed]

26. Xu, Z.; Parra, D.; Gómez, D.; Salinas, I.; Zhang, Y.A.; Von, G.J.L.; Heinecke, R.D.; Buchmann, K.; LaPatra, S.; Sunyer, J.O. Teleost skin, an ancient mucosal surface that elicits gut-like immune responses. Proc. Natl. Acad. Sci. USA 2013, 110, 13097-13102. [CrossRef] [PubMed]

27. Xia, H.; Liu, W.J.; Wu, K.; Wang, W.M.; Zhang, X.Z. sIgZ exhibited maternal transmission in embryonic development and played a prominent role in mucosal immune response of Megalabrama amblycephala. Fish Shellfish Immunol. 2016, 54, 107-117. [CrossRef] [PubMed]

28. Giacomelli, S.; Buonocore, F.; Albanese, F.; Scapigliati, G.; Gerdol, M.; Oreste, U.; Coscia, M.R. New insights into evolution of IgT genes coming from Antarctic teleosts. Mar. Genom. 2015, 24, 55-68. [CrossRef] [PubMed]

29. Xu, T.; Zhang, X.H. Edwardsiella tarda: An intriguing problem in aquaculture. Aquaculture 2014, 431, 129-135. [CrossRef]

30. Aoki, T.; Hirono, I. Immune relevant genes of Japanese flounder, Paralichthys olivaceus. Comp. Biochem. Physiol. D 2006, 1, 115-121. [CrossRef] [PubMed]

31. Lee, U.H.; Pack, H.J.; Do, J.W.; Bang, J.D.; Cho, H.R.; Ko, B.K. Flounder (Paralichthys olivaceus) cDNA encoding a secreted immunoglobulin M heavy chain. Fish Shellfish Immunol. 2001, 11, 537-540. [CrossRef] [PubMed]

32. Bengtén, E.; Quiniou, S.M.; Stuge, T.B.; Katagiri, T.; Miller, N.W.; Clem, L.W.; Warr, G.W.; Wilson, M. The IgH locus of the channel catfish, Ictalurus punctatus, contains multiple constant region gene sequences: Different genes encode heavy chains of membrane and secreted IgD. J. Immunol. 2002, 169, 2488-2497. [CrossRef] [PubMed]

33. Tian, J.Y.; Sun, B.J.; Luo, Y.P.; Zhang, Y.A.; Nie, P. Distribution of IgM, IgD and IgZ in mandarin fish, Siniperca chuatsi lymphoid tissues and their transcriptional changes after Flavobacterium columnare stimulation. Aquaculture 2009, 288, 14-21. [CrossRef]

34. Woof, J.M.; Mestecky, J. Mucosal immunoglobulins. Immunol. Rev. 2005, 206, 64-82. [CrossRef] [PubMed]

35. Salinas, I.; Zhang, Y.A.; Sunyer, J.O. Mucosal immunoglobulins and B cells of teleost fish. Dev. Comp. Immunol. 2011, 35, 1346-1365. [CrossRef] [PubMed]

36. Hirono, I.; Nam, B.H.; Enomoto, J.; Uchino, K.; Aoki, T. Cloning and characterisation of a cDNA encoding Japanese flounder Paralichthys olivaceus IgD. Fish Shellfish Immunol. 2003, 15, 63-70. [CrossRef]

37. Srisapoome, P.; Ohira, T.; Hirono, I.; Aoki, T. Genes of the constant regions of functional immunoglobulin heavy chain of Japanese flounder, Paralichthys olivaceus. Immunogenetics 2004, 56, 292-300. [CrossRef] [PubMed]

38. Beale, D.; Feinstein, A. Structure and function of the constant regions of immunoglobulins. Q. Rev. Biophys. 1976, 9, 135-180. [CrossRef] [PubMed]

39. Elfakess, R.; Dikstein, R. A translation initiation element specific to mRNAs with very short $5^{\prime}$-UTR that also regulates transcription. PLOS ONE 2008, 3, e3094. [CrossRef] [PubMed]

40. Moor, C.H.; Meijer, H.; Lissenden, S. Mechanisms of translational control by the $3^{\prime}$-UTR in development and differentiation. Semin. Cell Dev. Boil. 2005, 16, 49-58. [CrossRef] [PubMed]

41. Wilkie, G.S.; Dickson, K.S.; Gray, N.K. Regulation of mRNA translation by 5 '-and 3'-UTR-binding factors. Trends Biochem. Sci. 2003, 28, 182-188. [CrossRef]

42. Mazumder, B.; Seshadri, V.; Fox, P.L. Translational control by the $3^{\prime}$-UTR: The ends specify the means. Trends Biochem. Sci. 2003, 28, 91-98. [CrossRef] 
43. Kato, G.; Takano, T.; Sakai, T.; Matsuyama, T.; Sano, N.; Nakayasu, C. Cloning and expression analyses of a unique IgT in ayu Plecoglossus altivelis. Fish. Sci. 2014, 81, 29-36. [CrossRef]

44. Tariku Markos, T.; Kristoffer, L.K.; Ivar, H. Molecular cloning of IgT from Atlantic salmon, and analysis of the relative expression of $\tau, \mu$, and $\delta$ in different tissues. Vet. Immunol. Immunopathol. 2011, 139, 17-26.

45. Liu, Y.; Zhang, S.C.; Jiang, G.L.; Yang, D.; Lian, J.H.; Yang, Y.W. The development of the lymphoid organs of flounder, Paralichthys olivaceus, from hatching to 13 months. Fish Shellfish Immunol. 2004, 16, 621-632. [CrossRef] [PubMed]

46. Press, C.M.; Evensen, Ø. The morphology of the immune system in teleost fishes. Fish Shellfish Immunol. 1999, 9, 309-318. [CrossRef]

47. Ototake, M.; Iwama, G.K.; Nakanishi, T. The uptake of bovine serum albumin by the skin of bath-immunised rainbow trout Oncorhynchus mykiss. Fish Shellfish Immunol. 1996, 6, 321-333. [CrossRef]

48. Kato, G.; Takano, T.; Sakai, T.; Matsuyama, T.; Nakayasu, C. Vibrio anguillarum bacterin uptake via the gills of Japanese flounder and subsequent immune responses. Fish Shellfish Immunol. 2013, 35, 1591-1597. [CrossRef] [PubMed]

49. Hart, S.; Wrathmell, A.B.; Harris, J.E.; Grayson, T.H. Gut immunology in fish: A review. Dev. Comp. Immunol. 1988, 12, 453-480. [CrossRef]

50. Castro, R.; Jouneau, L.; Pham, H.P.; Bouchez, O.; Giudicelli, V.; Lefranc, M.P.; Fillatreau, S. Teleost fish mount complex clonal IgM and IgT responses in spleen upon systemic viral infection. PLoS Pathog. 2013, 9, e1003098. [CrossRef] [PubMed]

51. Li, Q.; Zhan, W.B.; Xing, J.; Sheng, X.Z. Production, characterization and applicability of monoclonal antibodies to immunoglobulin of Japanese flounder (Paralichthys olivaceus). Fish Shellfish Immunol. 2007, 23, 982-990. [CrossRef] [PubMed]

52. Xu, G.J.; Sheng, X.Z.; Xing, J.; Zhan, W.B. Effect of temperature on immune response of Japanese flounder (Paralichthys olivaceus) to inactivated lymphocystis disease virus (LCDV). Fish Shellfish Immunol. 2011, 30, 525-531. [CrossRef] [PubMed]

53. Gao, Y.L.; Tang, X.Q.; Sheng, X.Z.; Xing, J.; Zhan, W.B. Immune responses of flounder Paralichthys olivaceus vaccinated by immersion of formalin-inactivated Edwardsiella tarda following hyperosmotic treatment. Dis. Aquat. Organ. 2015, 116, 111-120. [CrossRef] [PubMed]

54. Du, Y.; Tang, X.Q.; Sheng, X.Z.; Xing, J.; Zhan, W.B. Immune response of flounder (Paralichthys olivaceus) was associated with the concentration of inactivated Edwardsiella tarda, and immersion time. Vet. Immunol. Immunopathol. 2015, 167, 44-50. [CrossRef] [PubMed]

55. Altschul, S.F.; Gish, W.; Miller, W.; Myers, E.W.; Lipman, D.J. Basic local alignment search tool. J. Mol. Biol. 1990, 215, 403-410. [CrossRef]

56. Rombel, I.T.; Sykes, K.F.; Rayner, S.; Johnston, S.A. ORF-FINDER: A vector for high-throughput gene identification. Gene 2002, 282, 33-41. [CrossRef]

57. Falquet, L.; Pagni, M.; Bucher, P.; Hulo, N.; Sigrist, C.J.; Hofmann, K.; Bairoch, A. The PROSITE database, its status in 2002. Nucleic Acids Res. 2002, 30, 235-238. [CrossRef] [PubMed]

58. Tusnády, G.E.; Dosztányi, Z.; Simon, I. TMDET: Web server for detecting transmembrane regions of proteins by using their 3D coordinates. Bioinformatics 2005, 21, 1276-1277. [CrossRef] [PubMed]

59. Gupta, R.; Jung, E.; Brunak, S. NetNGlyc 1.0 Server. Center for biological sequence analysis, technical university of Denmark. Available online: http://www.cbs.dtudk/services/NetNGlyc (accessed on 15 September 2016).

60. Thompson, J.D.; Higgins, D.G.; Gibson, T.J. CLUSTAL W: Improving the sensitivity of progressive multiple sequence alignment through sequence weighting, position-specific gap penalties and weight matrix choice. Nucleic Acids Res. 1994, 22, 4673-4680. [CrossRef] [PubMed]

61. Tamura, K.; Peterson, D.; Peterson, N.; Stecher, G.; Nei, M.; Kumar, S. MEGA5: Molecular evolutionary genetics analysis using maximum likelihood, evolutionary distance, and maximum parsimony methods. Mol. Biol. Evol. 2011, 28, 2731-2739. [CrossRef] [PubMed]

62. Gasteiger, E.; Gattiker, A.; Hoogland, C.; Ivanyi, I.; Appel, R.D.; Bairoch, A. ExPASy: The proteomics server for in-depth protein knowledge and analysis. Nucleic Acids Res. 2003, 31, 3784-3788. [CrossRef] [PubMed] 
63. Livak, K.J.; Schmittgen, T.D. Analysis of relative gene expression data using real-time quantitative PCR and the $2^{-\Delta \Delta C t}$ method. Methods 2001, 25, 402-408. [CrossRef] [PubMed]

64. Ingerslev, H.C.; Pettersen, E.F.; Jakobsen, R.A.; Petersen, C.B.; Wergeland, H.I. Expression profiling and validation of reference gene candidates in immune relevant tissues and cells from Atlantic salmon (Salmo salar, L.). Mol. Immunol. 2006, 43, 1194-1201. [CrossRef] [PubMed]

(c) 2016 by the authors; licensee MDPI, Basel, Switzerland. This article is an open access article distributed under the terms and conditions of the Creative Commons Attribution (CC-BY) license (http:/ / creativecommons.org/licenses/by/4.0/). 